\title{
Atg7 is required for acrosome biogenesis during spermatogenesis in mice
}

Hongna Wang ${ }^{1,2}$, Haifeng Wan ${ }^{1}$, Xixia Li ${ }^{1,2}$, Weixiao Liu ${ }^{1}$, Qi Chen ${ }^{1}$, Yaqing Wang ${ }^{3}$, Lin Yang ${ }^{3}$, Hongmei Tang ${ }^{4}$, Xiujun Zhang ${ }^{4}$, Enkui Duan ${ }^{1}$, Xiaoyang Zhao ${ }^{1}$, Fei Gao ${ }^{1}$, Wei $\mathrm{Li}^{1}$

${ }^{1}$ State Key Laboratory of Reproductive Biology, Institute of Zoology, Chinese Academy of Sciences, Beijing 100101, China; ${ }^{2}$ University of Chinese Academy of Sciences, Beijing 100049, China; ${ }^{3}$ State Key Laboratory of Molecular Developmental Biology, Institute of Genetics and Developmental Biology, Chinese Academy of Sciences, Beijing 100101, China; ${ }^{4}$ College of Life Sciences, Hebei United University, Tangshan, Hebei 063000, China

The acrosome is a specialized organelle that covers the anterior part of the sperm nucleus and plays an essential role in the process of fertilization. The molecular mechanism underlying the biogenesis of this lysosome-related organelle (LRO) is still largely unknown. Here, we show that germ cell-specific Atg7-knockout mice were infertile due to a defect in acrosome biogenesis and displayed a phenotype similar to human globozoospermia; this reproductive defect was successfully rescued by intracytoplasmic sperm injections. Furthermore, the depletion of Atg7 in germ cells did not affect the early stages of development of germ cells, but at later stages of spermatogenesis, the proacrosomal vesicles failed to fuse into a single acrosomal vesicle during the Golgi phase, which finally resulted in irregular or nearly round-headed spermatozoa. Autophagic flux was disrupted in Atg7-depleted germ cells, finally leading to the failure of LC3 conjugation to Golgi apparatus-derived vesicles. In addition, Atg7 partially regulated another globozoospermia-related protein, Golgi-associated PDZ- and coiled-coil motif-containing protein (GOPC), during acrosome biogenesis. Finally, the injection of either autophagy or lysosome inhibitors into testis resulted in a similar phenotype to that of germ cell-specific Atg7-knockout mice. Altogether, our results uncover a new role for Atg7 in the biogenesis of the acrosome, and we provide evidence to support the autolysosome origination hypothesis for the acrosome.

Keywords: acrosome biogenesis; autolysosome; autophagy; globozoospermia; Atg7

Cell Research (2014) 24:852-869. doi:10.1038/cr.2014.70; published online 23 May 2014

\section{Introduction}

The acrosome is a unique membranous organelle located over the anterior part of the sperm nucleus. It plays an important role in the dispersion of cumulus cells and/or sperm penetration of the zona pellucida of the oocyte during fertilization $[1,2]$. Acrosome biogenesis begins with the initial phase of spermatid development and has been described as follows: in the Golgi phase of spermatogenesis, numerous proacrosomic granules are

Correspondence: Wei $\mathrm{Li}^{\mathrm{a}}, \mathrm{Fei} \mathrm{Gao}{ }^{\mathrm{b}}$

${ }^{a}$ Tel: 86-10-64807529; Fax: 86-10-64806480

E-mail: leways@ioz.ac.cn

${ }^{\text {b}}$ Tel: 86-10-64807593; Fax: 86-10-64806480

E-mail: gaof@ioz.ac.cn

Received 6 November 2013; revised 13 March 2014; accepted 14 April 2014; published online 23 May 2014 formed from trans-Golgi stacks, and they are transported to and accumulate in the concave region of the nuclear surface; they then fuse with each other to form a single large acrosomic granule that attaches to the nucleus. In the next cap phase, the acrosome expands and begins to cover the nucleus like a cap. During the subsequent acrosome and maturation phases, the acrosome stops growing but changes its morphology. After a series of highly complex morphological changes, such as spermatid elongation and cytoplasm removal, spermiogenesis ends with the production of mature sperm [2,3]. Although the morphogenetic changes during acrosome biogenesis have been well-documented, the precise molecular mechanism underlying this process is still largely unknown.

The acrosome is regarded as a modified lysosome [4] or a novel lysosome-related organelle (LRO) [2, 3]. However, the lysosome in mammalian cells is smaller than the acrosome. How the lysosomes are modified to 
make an acrosome is a longstanding question in the field. One possibility is that the lysosome first fuses with an autophagosome to form a relatively large autolysosome, and the acrosome actually originates from the modification of the autolysosome. An immediate prediction of this working hypothesis is that autophagy should be involved in acrosome biogenesis.

Macroautophagy (hereafter referred to as autophagy) is the primary intracellular catabolic mechanism for degrading and recycling long-lived proteins and organelles. It is characterized by the engulfment of cytoplasmic material by a double-membrane vesicle, known as the autophagosome. Autophagosomes move along cytoskeletal structures and fuse with lysosomes, forming an autolysosome, in which both the autophagosome membrane and contents are degraded by resident hydrolases [5-8]. The molecular machinery of autophagy is evolutionarily conserved from yeast to mammals. Two ubiquitin-like conjugation systems, Autophagy-related gene 12 (Atg12)-Atg5 and LC3-lipid/membrane, are the core machinery for autophagosome formation. Atg7, which is homologous to the ubiquitin-activating enzyme E1 (Uba1), encodes the E1-like enzyme that is essential to these conjugation systems [8] and is indispensable for both selective and nonselective autophagy induction. In an ATP-dependent manner, Atg12 is activated by Atg7, transferred to the ubiquitin-conjugating-like enzyme Atg10, then to the target protein Atg5 to form an Atg12Atg5 conjugate, which finally recruited Atg16 to form a multimeric complex. This complex might function as an E3 ubiquitin ligase for the second ubiquitin-like conjugation system, LC3-lipid/membrane conjugation. LC3 is also activated by Atg7, transferred to another E2-like enzyme (Atg3), and finally conjugated to lipid/membrane. As an integral membrane protein, LC3-lipid/membrane is a scaffold candidate to drive membrane expansion and vesicle completion. Finally, LC3 residing on the outer face of the vesicle can be liberated by Atg 4 and used in another conjugation reaction, whereas LC 3 on the inner surface is eventually degraded in autolysosomes [6-8].

The primary function of autophagy is to allow lower eukaryotic organisms such as yeast to survive nutrient starvation conditions by recycling cellular components in response to either extracellular or intracellular stresses. In addition to its established roles in regulating nutrient supply and adaptation to stress conditions, autophagy functions in many physiological processes in mammalian systems, such as cell growth, antiaging mechanisms, intracellular quality control and renovation during development and differentiation [5].

To study the role of autophagy in spermatogenesis, we selected Atg7 to be knocked out in mouse to inves- tigate whether autophagy affects acrosome biogenesis. As the knockout of autophagy-related genes in mouse results in either embryonic lethality or perinatal death $[5,9]$, we could not test our working hypothesis directly through the conventional knockout of Atg7. To overcome this obstacle, Atg7 was specifically inactivated in germ cells to explore the functions of autophagy in acrosome biogenesis. Interestingly, we found that Atg7-mutant male mice showed almost complete infertility with aberrant acrosome formation, which was similar to human globozoospermia, a severe fertility disorder characterized by abnormal round-headed spermatozoa. Further study revealed that the defect of acrosome formation in Atg7-knockout mice was most likely due to the failure of Golgi-derived proacrosomal vesicle fusion and/or membrane trafficking. Thus, our findings uncover a novel and critical function of Atg7 in the process of acrosome biogenesis, and they support the autolysosome origination hypothesis for acrosome formation.

\section{Results}

Germ cell-specific knockout of Atg7 causes male infertility in mice

To overcome the obstacle of embryonic lethality or postnatal death in mice deficient in autophagy-related genes, Atg7 was specifically inactivated in germ cells by crossing the $\operatorname{Atg} 7^{\text {Flox } / F l o x}$ and TNAP-Cre mouse strains [10]. Because the expression of TNAP-Cre is specific to primordial germ cells, this inactivation resulted in a germ cell-specific Atg7-knockout mouse, hereafter called TNAP-Atg $7^{\prime-}$.

We first tested the Atg7 knockout efficiency in TNAP$\operatorname{Atg} 7^{/-}$mice by western blotting. As shown in Figure 1A, the protein level of Atg7 was dramatically reduced in the testes of TNAP-Atg $7^{-1-}$ mice compared with TNAP$\operatorname{Atg} 7^{+/-}$and $\operatorname{Atg} 7^{F l o x} / F$ lox mice. The fertility of male mice was then assessed by mating 11-13 males of each strain with $\operatorname{Atg} 7^{\text {Flox/Flox }}$ females over a 2-month period. As shown in Figure 1B, only $8.14 \%$ of the females were pregnant after mating with $T N A P-A \operatorname{tg} 7^{-/-}$male mice compared with an $87.01 \%$ rate of pregnancy after mating with $\operatorname{Atg} 7^{\text {Flox } F \text { Flox }}$ males. The partial fertility of $T N A P$ $\operatorname{Atg} 7^{-1}$ male mice presumably was due to the efficiency of TNAP-Cre because we found some $\operatorname{Atg} 7^{F l o x /+}$ mice but no $\operatorname{Atg} 7^{+/-}$mice in the offspring of $T N A P-A \operatorname{tg} 7^{-1-}$ male mice (data not shown). In addition, the size (Figure 1C) and weight of testes (Figure 1D) from TNAP-Atg $7^{--}$mice were significantly reduced compared with those of Atg$7^{\text {Flox/Flox }}$ mice. The results of histology study showed that although the diameters of round seminiferous tubules in $T N A P-A \operatorname{tg} 7^{-1}$ mice were comparable to those in $\operatorname{Atg} 7^{\text {Flox }}$ 
A

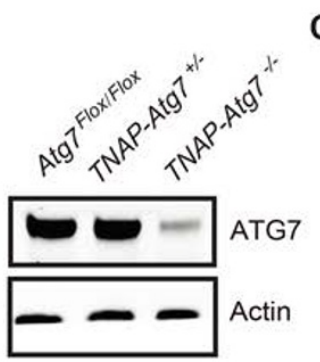

C

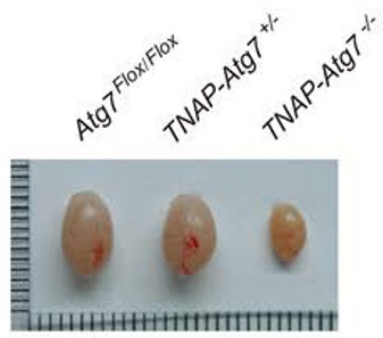

B

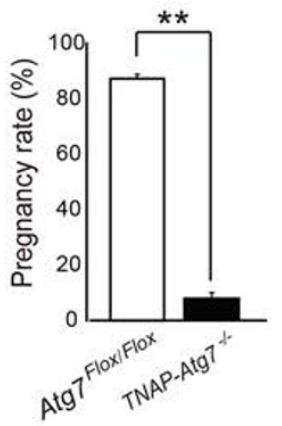

D

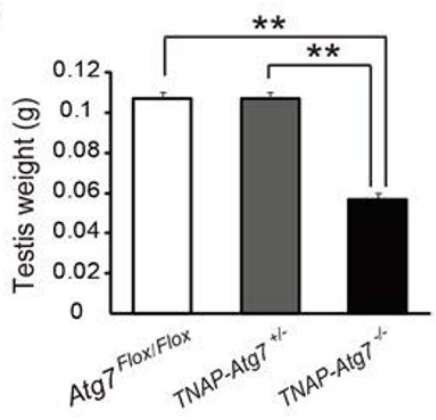

E

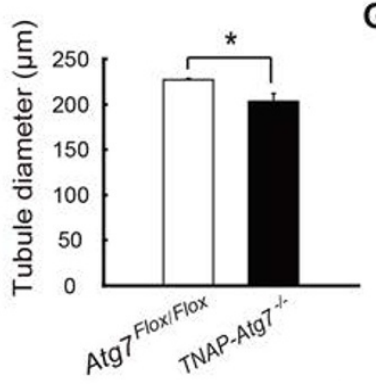

$\mathbf{F}$

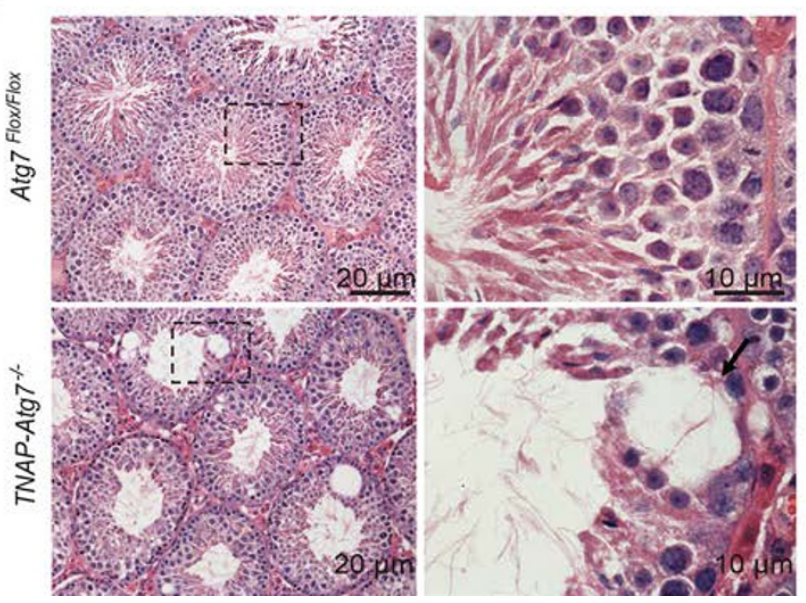

Figure 1 Severe reproductive defects in TNAP-Atg $7^{-1}$ males. (A) The Atg7 protein level was dramatically reduced in the testes of TNAP-Atg $7^{-1-}$ mice. (B) Fertility test: $87.01 \pm 1.26 \%$ of the plugged females were pregnant after crossing with $A \operatorname{tg} 7^{\text {Flox/Flox }}$ males, whereas only $8.14 \pm 0.29 \%$ of the plugged females were pregnant after crossing with $T N A P-A \operatorname{tg} 7^{-1}$ males. (C) The testes of TNAP-Atg $7^{-1-}$ mice were smaller than those of the Atg $7^{\text {Flox/Flox }}$ mice. (D) The weight of the testes of TNAP-Atg $7^{-/-}$mice was reduced compared with that of $A \operatorname{tg} 7^{\text {Flox/Flox }}$ mice. Atg $7^{\text {Flox/Flox }}, 0.11 \pm 0.00 \mathrm{~g} ;$ TNAP-Atg $^{+/-}, 0.11 \pm 0.00 \mathrm{~g} ;$ TNAP-Atg $^{-/-}$ mice, $0.06 \pm 0.00 \mathrm{~g}$. (E) The diameter of the seminiferous tubules in the TNAP-Atg $7^{-/-}$mice was similar to that of the Atg $7^{F / 0 x / F l o x}$ mice. TNAP-Atg $7^{-/}, 203.33 \pm 8.82 \mu \mathrm{m}$; Atg $7^{\text {Flox/Flox }}, 227.33 \pm 1.45 \mu \mathrm{m}$. (F) The histology of the seminiferous tubules of $A \operatorname{tg} 7^{\text {Flox } /}$ Flox and TNAP-Atg $7^{-/}$mice. (G) Vacuoles were observed in the seminiferous tubules of the TNAP-Atg $7^{-/}$testis. TNAP-Atg $7^{-/}$, $36.67 \pm 5.70 \%$ of tubules contained vacuoles; $\operatorname{Atg} 7^{\text {Flox/Flox }}, 1.33 \pm 0.33 \%$ of tubules contained vacuoles.

${ }^{\text {Flox }}$ mice (Figure 1E), a substantial portion of the tubule structure was disorganized with large vacuoles in TNAP$\operatorname{Atg} 7^{\prime-}$ compared with the normal seminiferous tubules in the $\operatorname{Atg} 7^{\text {Flox } F \text { Flox }}$ male siblings (Figure $1 \mathrm{~F}$ and $1 \mathrm{G}$ ). Those vacuoles in the tubule lumens usually come from dead germ cells [11]. We next used terminal deoxynucleotidyl transferase dUTP nick end labeling assay to investigate whether there was apoptosis in those germ cells. A significant number of apoptotic cells were found in TNAP$\operatorname{Atg} 7^{-/-}$mouse testes compared with those in the $\operatorname{Atg} 7^{\text {Flox } /}$ Flox mice (Supplementary information, Figure S1A). These results are consistent with a previous report [11] and suggest that those vacuoles might come from dead germ cells. However, even in the testis of the TNAP$\operatorname{Atg} 7^{-1}$ mice, no more than $0.5 \%$ of the germ cells died by apoptosis (Supplementary information, Figure S1B). Together with the fact that some spermatozoa were still produced from the TNAP-Atg $7^{-1}$ mouse testes, our re- sults indicate that germ cell death did not account for the subfertility of $T N A P-A \operatorname{tg} 7^{--}$male mice.

\section{TNAP-Atg $7^{-/}$mice produce round-headed spermatozoa}

The histological analysis showed that many detached premature germ cells and abnormal spermatozoa were found in the cauda epididymis of TNAP-Atg $7^{-1}$ mice but not in the $\operatorname{Atg} 7^{\text {Flox Flox }}$ mice (Figure 2A). The total number of spermatozoa in the cauda epididymis was dramatically reduced in TNAP-Atg $7^{-1-}$ mice $\left(6.73 \times 10^{6}\right.$ versus 21.37 $\times 10^{6}$ in $A \operatorname{tg} 7^{\text {Flox/Flox }}$ mice) (Figure 2B). Morphological evaluation revealed that many spermatozoa from TNAP$\operatorname{Atg} 7^{--}$mice had irregularly shaped round heads (Figure $2 \mathrm{C}$ and $2 \mathrm{D}$ ), which is similar to human globozoospermia, a rare but severe fertility disorder characterized by round-headed spermatozoa with malformed acrosome or without acrosome at all [12]. To test whether Atg7 knockout has any impact on acrosomes, single-sperm immuno- 
fluorescence was performed using the acrosome-specific marker sp56. The acrosomes of spermatozoa from TNAP$\operatorname{Atg} 7^{-1-}$ mice showed various defects, such as mislocalization, deformation and fragmentation; thus, they failed to acquire the typical crescent moon shape (Figure 2E). To investigate the effect of Atg7 knockout on acrosome function, we performed the acrosome reaction analysis. Because A23187 is a $\mathrm{Ca}^{2+}$ ionophore that can induce the release of acrosomal contents, the acrosome reaction could be induced by adding A23187 to freshly isolated spermatozoa. The acrosome reaction was then monitored by Pisum sativum agglutinin (PSA) staining; only intact acrosomes could be stained by PSA, and once they broke after the acrosome reaction, spermatozoa could not be stained by PSA [13]. Before induction, we found that the rates of spontaneous acrosome reaction were comparable between $\operatorname{Atg} 7^{\text {Flox/Flox }}$ and the knockout mice $(28.03 \%$ versus $34.58 \%$, Figure $2 \mathrm{~F}$ and $2 \mathrm{G}$ ). However, after acrosome reaction, $63.87 \%$ of the spermatozoa in $\operatorname{Atg} 7^{\text {Flox/Flox }}$ mice lost their PSA-positive structures, while most of the spermatozoa were still stained by PSA in TNAP-Atg $7^{-/-}$ mice (Figure $2 \mathrm{~F}$ and $2 \mathrm{H}$ ), suggesting that spermatozoa of $T N A P-\operatorname{Atg} 7^{-1}$ mice failed to release their acrosomal contents.

To test whether the infertility of $T N A P-A \operatorname{tg} 7^{--}$mice was mainly due to an acrosome defect, we tested the spermatozoa fertility of $T N A P-\operatorname{Atg} 7^{-1-}$ mice employing in vivo fertilization and intracytoplasmic sperm injection (ICSI). The in vivo fertilization results showed that the spermatozoa from the TNAP-Atg $7^{-1-}$ mice could not fertilize eggs of $\operatorname{Atg} 7^{\text {Flox/Flox }}$ females (Supplementary information, Figure S2). After three ICSIs with spermatozoa from TNAP-Atg $7^{-1}$ mice, we obtained 17 healthy offspring (Supplementary information, Figure S3A). All of these offspring were $\operatorname{Atg} 7^{+/-}$mice, as demonstrated by genotyping (Supplementary information, Figure S3C). This result suggests that an acrosome defect might be the major cause of the infertility of $T N A P-\operatorname{Atg} 7^{-1-}$ mice because once overcoming the fertilization stage, spermatozoa from TNAP-Atg $7^{-1}$ mice were sufficient to support the later stages' development of a new embryo. Together, these results suggest that Atg7 is involved in acrosome biogenesis and may be involved in the pathogenesis of globozoospermia.

\section{Abnormal acrosome biogenesis in TNAP-Atg $7^{-1-}$ mice}

To examine how Atg7 knockout affects acrosome biogenesis, the acrosome at different stages of spermiogenesis was labeled with an antibody against the acrosome membrane protein Afaf [14]. As shown in Figure 3A, proacrosomal vesicles derived from the Golgi apparatus were fused into a single acrosomal vesicle attached to one end of the nucleus in the Golgi-phase spermatids of $\operatorname{Atg} 7^{\text {Flox/Flox }}$ mice. However, in Atg7-deficient mice, multiple small vesicles were localized to the perinuclear region without fusing with each other in approximately $30 \%$ of the Golgi-phase spermatids (Figure 3B and 3C). In the cap phase, as indicated by Afaf staining, the acrosome grew into a single cap-like structure that covered the nuclei in $\operatorname{Atg} 7^{\text {Flox Flox }}$ spermatids (Figure 3A). However, more than $20 \%$ of the spermatids still had several acrosomal vesicles or aggregates in the $T N A P-A \operatorname{tg} 7^{-1-}$ mice (Figure 3B and 3D). Hook-shaped acrosomes were observed in the elongated spermatids of $\operatorname{Atg} 7^{\text {Flox/Flox }}$ mice (Supplementary information, Figure S4A). By contrast, many irregular or nearly round Afaf-positive structures (24.48\%) were found in TNAP-Atg $7^{1-}$ mice, and it was difficult to accurately identify the stage (Supplementary information, Figure S4B and S4C). These results suggest that acrosome biogenesis was affected in the TNAP$\operatorname{Atg} 7^{-1}$ mice.

To further characterize and confirm the defects of acrosome formation in $T N A P-A \operatorname{tg} 7^{-/-}$mice, transmission electron microscopy (TEM) analysis was performed. In the $\operatorname{Atg} 7^{\text {Flox/Flox }}$ mice, all four acrosome biogenesis phases were identified by their standard characteristics, such as the progression of acrosome growth and the corresponding thickening of the nuclear envelope (Figure 3E and Supplementary information, Figure S5A). However, in Atg7-deficient spermatids, multiple acrosomal structures were found in the Golgi phase (Figure 3F). In addition to this defect, acrosome shrinkage was observed in Atg7-deficient spermatids in the cap phase due to the accumulated proacrosomal vesicles derived from the Golgi apparatus in comparison with the plump acrosomes in the spermatids of $\operatorname{Atg} 7^{\text {Flox/Flox }}$ mice (Figure $3 \mathrm{~F}$ ). These results suggest that the malformed acrosomes in TNAP-Atg $7^{-1-}$ mice most likely resulted from the failure of proacrosomal vesicles to fuse and be transported to the preacrosomal structure at one end of the nuclei, rather than abnormal fragmentation. In the subsequent stages of spermiogenesis, vacuolated or irregularly shaped acrosomes were observed in the spermatids of TNAP-Atg $7^{-1}$ mice, and the nucleus neighboring these malformed acrosomes showed less condensation or impairment in nuclear elongation, which resulted in round or irregularly shaped nuclei (Supplementary information, Figure S5B). Together, these results indicate that $A \operatorname{tg} 7$ participates in acrosome biogenesis starting in the Golgi phase.

\section{Autophagic flux is disrupted in the testis of TNAP-Atg7 $7^{-1}$ mice}

Given that Atg7 is an E1-like enzyme that is essential to autophagy induction, we first evaluated the effect of 
A
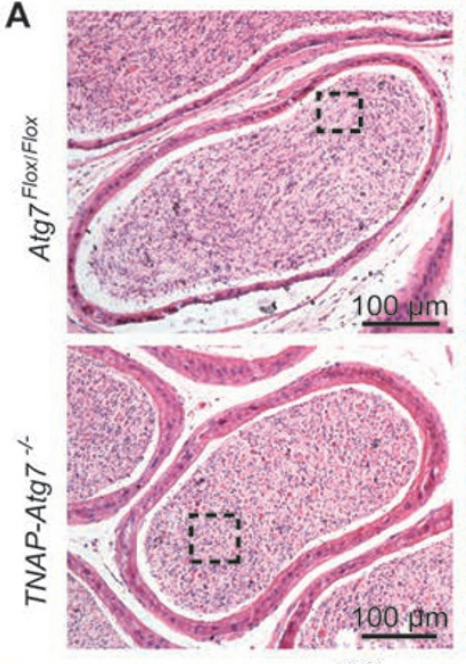

C

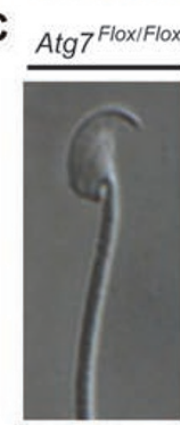

$\mathbf{F}$
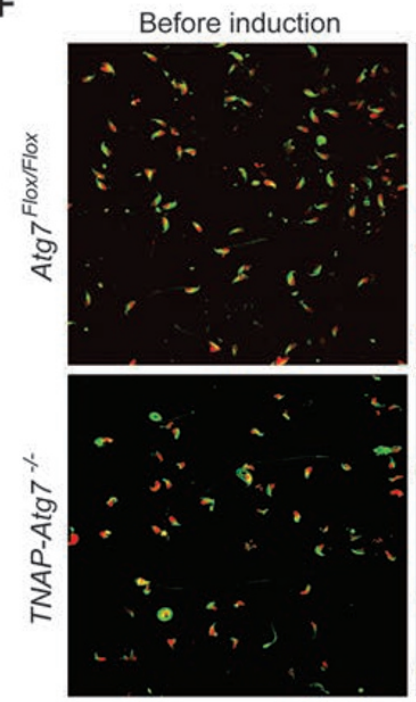

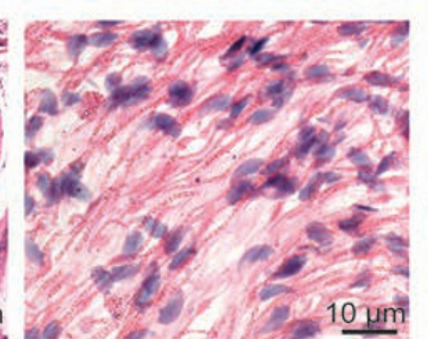

B
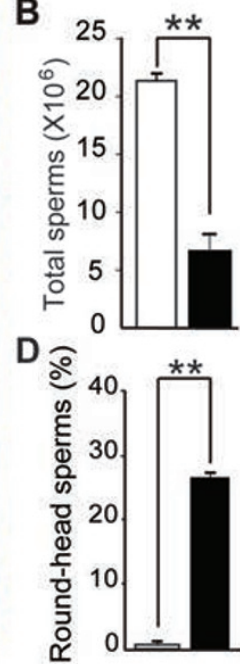

$\mathrm{E}_{\operatorname{Atg} 7^{\text {Flox } / \text { Flox }}}$

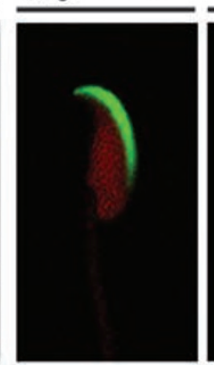

After induction
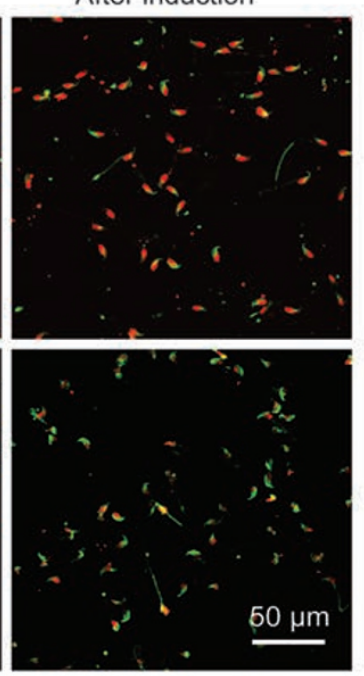

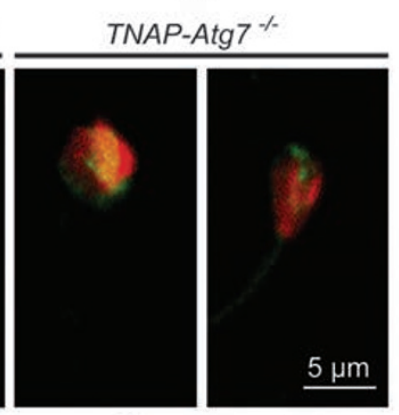

G

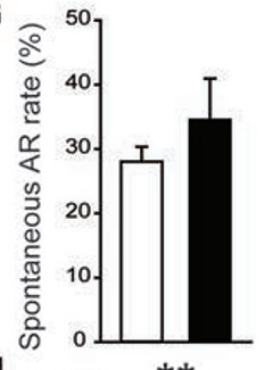

H

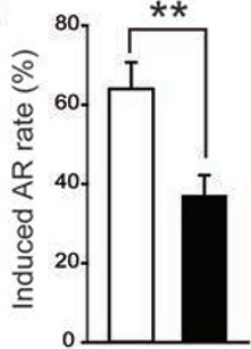

Figure 2 Defects of TNAP-Atg $7^{-/}$spermatozoa. (A) The histology of the cauda epididymis of $\operatorname{Atg} 7^{\text {Flox } F \text { Flox }}$ and $T N A P-A \operatorname{tg} 7^{-1-}$ mice. (B) The total number of sperms from the cauda epididymis was significantly decreased in TNAP-Atg $7^{\prime-}$ mice. $\operatorname{Atg} 7^{\text {Flox } F \text { Fox }}$ (white bar), $21.37 \pm 0.58 \times 10^{6} ;$ TNAP-Atg7 ${ }^{-1}$ (black bar), $6.73 \pm 1.47 \times 10^{6}$. (C) Confocal images show round-headed sperm in TNAP-Atg $7^{-1-}$ mice. (D) In TNAP-Atg $7^{-1-}$ mice (black bar), $26.80 \pm 0.09 \%$ of the sperm had abnormal globozoospermia-like morphology, whereas only $0.42 \pm 0.00 \%$ of the sperm had abnormal morphology in $A t g 7^{\text {Flox/Fox }}$ mice (white bar). (E) Immunofluorescence for the acrosome-specific marker sp56. Note that the acrosome was disrupted in TNAP-Atg ${ }^{-1 /}$ mice. (F) Acrosome reaction. PSA-FITC staining of spermatozoa from TNAP-Atg $7^{-1}$ mice (lower panel) and $A \operatorname{Atg} 7^{\text {Flox } x \text { Flox }}$ mice (upper panel) before (left panel) and after induction (right panel). Nuclei were stained with PI. Bar indicates $50 \mu \mathrm{m}$. (G) Spontaneous acrosome reaction rates of spermatozoa without induction. Atg ${ }^{\text {Flox Flox }}$ mice (white bar), $28.03 \pm 2.30 \%$; TNAP-Atg $7^{-1}$ (black bar), $34.58 \pm 6.35 \%$. $(\mathrm{H})$ Induced acrosome reaction rates of spermatozoa from the $A \operatorname{Atg} 7^{\text {FloxFlox }}$ and TNAP-Atg $7^{\prime-}$ mice. $\operatorname{Atg} 7^{\text {Flox } F \text { Ilox }}$ mice (white bar) $63.87 \pm 6.71 \%$; TNAP-Atg $7^{-{ }^{-}}$(black bar), $38.67 \pm 5.23 \%$. 
Atg7 deficiency on autophagic flux in the testis. Under starvation conditions, autophagy induction is dependent on mTOR and AMPK [15], and these two proteins are upstream of Atg7. Immunoblotting analysis showed that levels of total mTOR, phosphor-mTOR and phosphor-AMPK $\alpha$ were not changed between the TNAP$\operatorname{Atg} 7^{-1-}$ and the $\operatorname{Atg} 7^{F l o x / F l o x}$ mice, indicating that the germ cell-specific knockout of Atg7 did not affect upstream events of autophagy induction in the testis (Figure 4A). However, we observed a slightly increased level of phosphorylated p70S6 kinase (Figure 4A), suggesting enhanced protein synthesis in $T N A P-A t g 7^{-1}$ mouse testes. Similar to Spem1-knockout mice [16], we found that the polyubiquitinated protein level increased by 1.5-fold in Atg7-deficient testes compared with $\mathrm{Atg} 7^{\mathrm{Flox} /}$ Flox ones (Figure 4B and 4C), indicating the inhibition of protein degradation. Consistent with findings from Atg7 knockout in other tissues [9, 17, 18], LC3-I but not the membrane-associated form LC3-II was accumulated in Atg7-deficient testes (Figure 4D). In addition, the autophagic substrate SQSTM1/p62 was found to be accumulated by western blotting (Figure 4D) and immu-
A
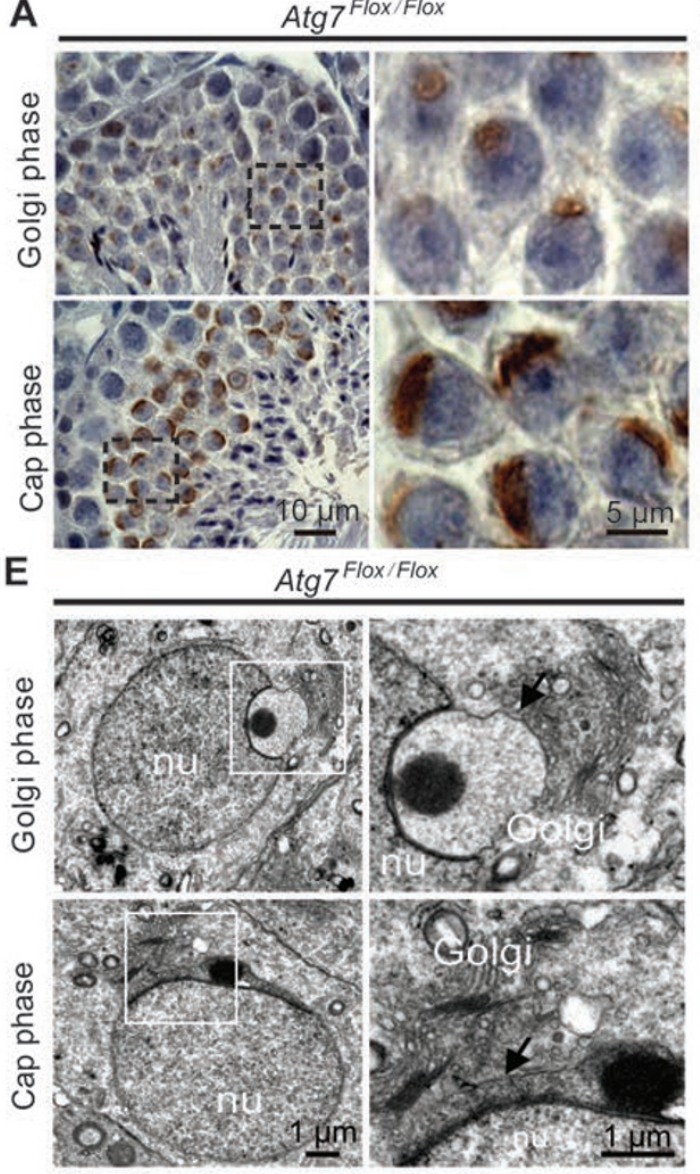

B
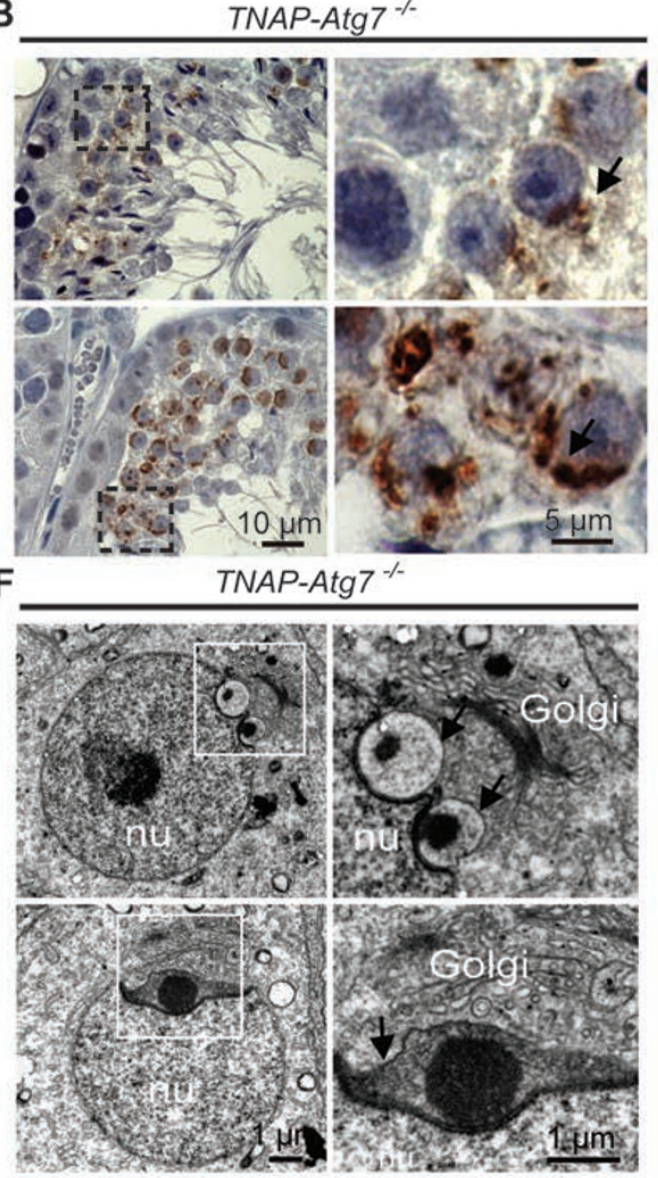

C

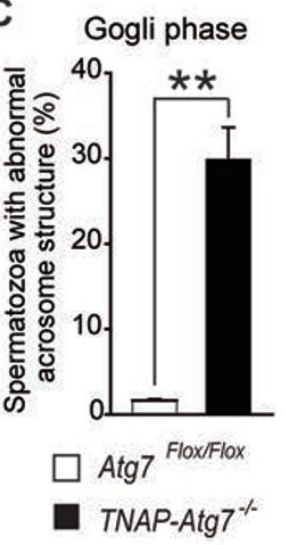

D

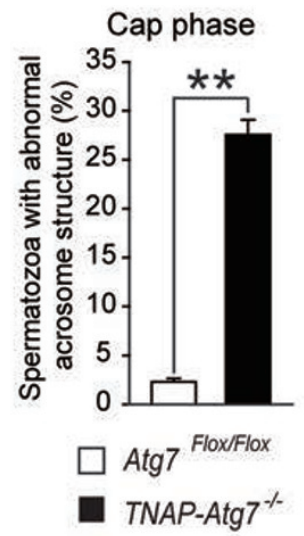

Figure 3 Abnormal acrosomal biogenesis of TNAP-Atg $7^{-1-}$ mice. (A) Afaf immunohistochemistry (IHC) of Atg $7^{\text {Flox/Flox }}$ testes. Upper and lower panels represent typical Golgi and cap phases, respectively. (B) Afaf IHC in TNAP-Atg $7^{-/-}$mouse testes. Fragmented acrosomes were observed in the Golgi and cap phases. Arrows indicate the locations of the acrosomes. Blue color indicates nuclei, and brown color indicates Afaf in A and B. (C, D) Quantification of the spermatocytes with abnormal acrosome structure in the Golgi and cap phases in A and B. Golgi phase: $\operatorname{Atg} 7^{\text {Flox/Flox }}, 1.64 \pm 0.16 \%$, TNAP-Atg $^{-/-}, 29.90 \pm$ 3.72\%; Cap phase: $A \operatorname{tg} 7^{\text {Flox/Flox }}, 2.29 \pm 0.35 \%$; TNAP-Atg7 $7^{-/-}, 27.56 \pm 1.52 \%$. (E) Ultrastructural analysis of the Atg $7^{\text {Flox/Flox }}$ spermatids in the Golgi and cap phases. In the Golgi phase, many vesicles began to aggregate to form proacrosomal granules. A single acrosome granule was attached to one pole of the nucleus. In the cap phase, the acrosome started to spread along the nucleus. (F) TEM images of the TNAP-Atg $7^{-1-}$ spermatids in the Golgi and cap phases. In the Golgi phase, two proacrosomal centers (arrows) were observed around the nucleus. In the cap phase, the acrosome did not spread normally along the nucleus, and many proacrosomal vesicles accumulated in the concave region near the trans-Golgi stacks. nu, nucleus; Golgi, Golgi apparatus. 
nofluorescence (Figure 4E). Taken together, these results indicate that autophagic flux was disrupted in Atg7-deficient testes.

Atg7 is involved in proacrosomal vesicle transportation and/or fusion into the acrosome

According to the autolysosome origin model, we hypothesized that Atg7 also operates as an E1-like en- zyme by initiating two Ubl conjugation systems (LC3 and Atg12) and conjugating LC3 to the lipid/membrane during spermatogenesis, and the conjugated LC3 might help the proacrosomal vesicle fuse and expand, which is similar to its function in the process of autolysosome formation $[5,6,8]$. To test this possibility, LC3 expression was examined in $\operatorname{Atg} 7^{\text {Flox/Flox }}$ testes during spermatogenesis. We found that LC3 was expressed in the round or
A

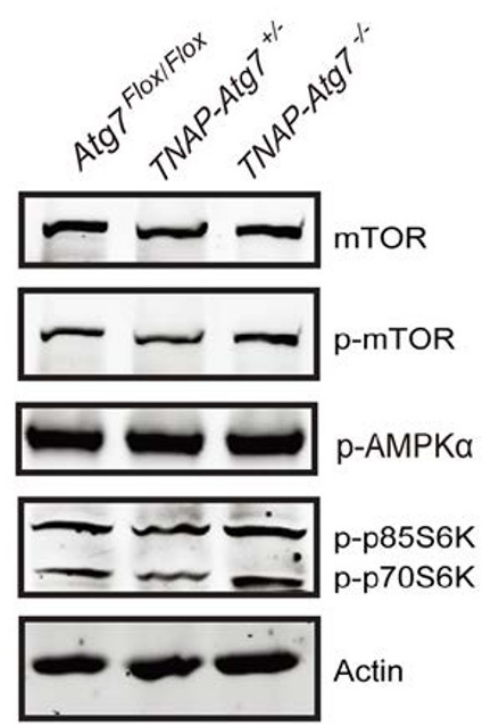

$\mathbf{E}$
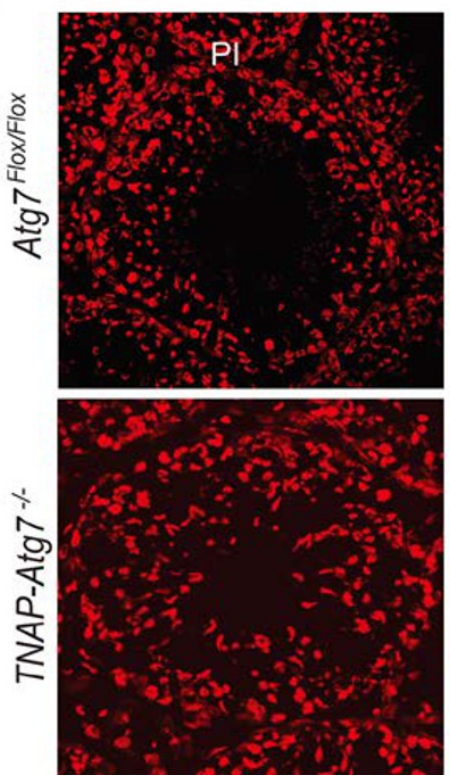

B
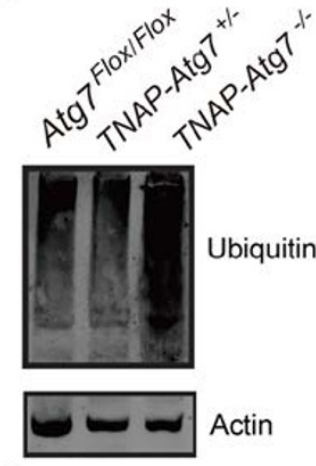

C

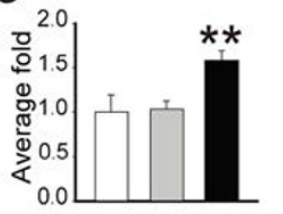

D
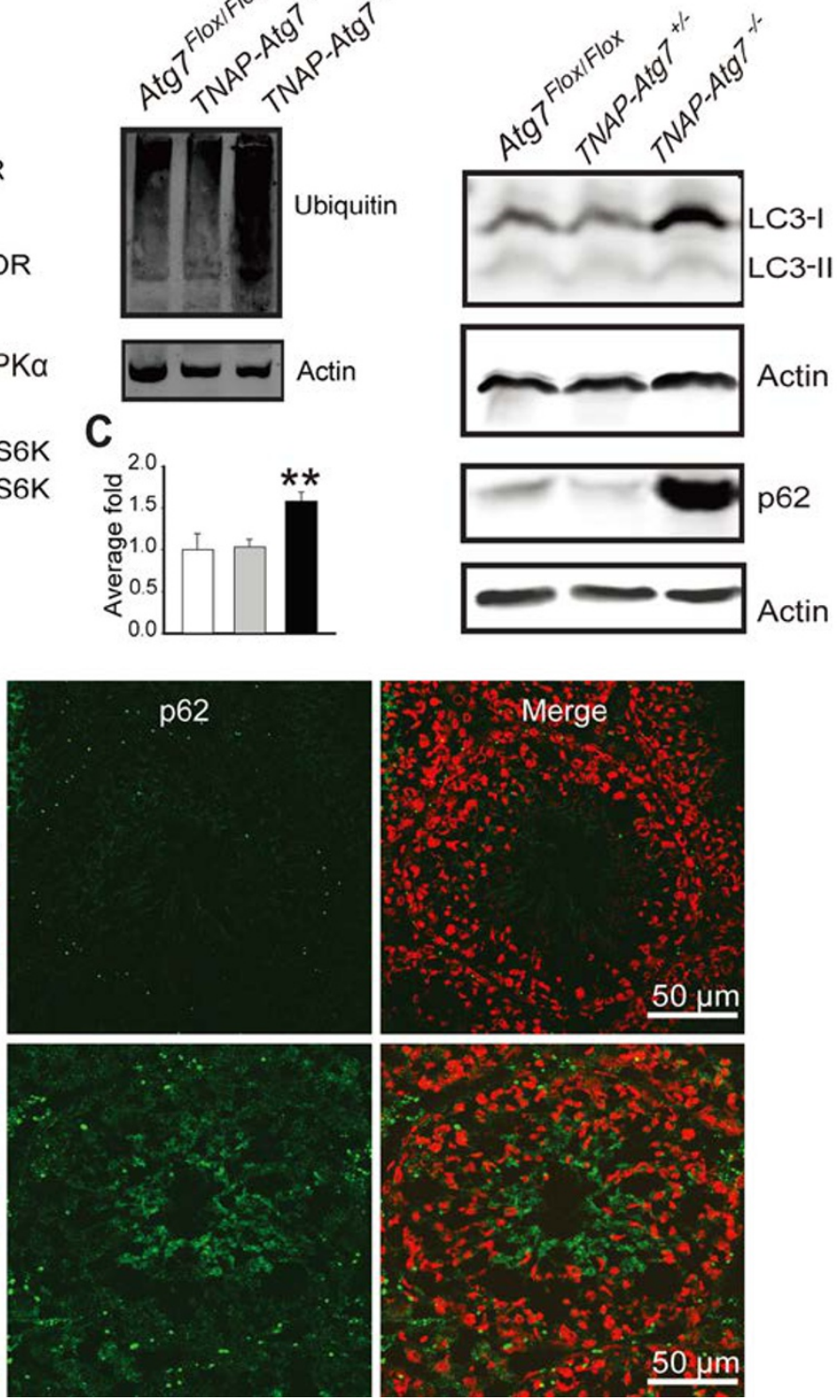

Figure 4 Autophagic flux is disrupted in the germ cells of male TNAP-Atg $7^{-1-}$ mice. (A) Immunoblot analysis of total mTOR, phosphor-mTOR, phosphor-AMPK $\alpha$, and phospho-p70S6K. (B) Immunoblot analysis of polyubiquitinated proteins. (C) Quantification of the ubiquitinated proteins (from four experiments) in the testes of $A \operatorname{tg} 7^{\text {Flox/Flox }}$ mice and the knockout mice. White bar, $\operatorname{Atg} 7^{\text {Flox/Flox }}(1.00 \pm 0.00)$; gray bar, TNAP-Atg $7^{+/-}(1.04 \pm 0.06)$; black bar, TNAP-Atg $7^{-/-}(1.56 \pm 0.04)$. (D) Immunoblot analysis of LC3 and p62. (E) Immunofluorescence detection of p62 in the seminiferous tubules of TNAP-Atg $7^{-/-}$and $A \operatorname{tg} 7^{\mathrm{Flox} / F \text { lox }}$ mice. 
elongating spermatids (Figure 5A, left), and higher magnification revealed that $\mathrm{LC} 3$ was localized in the perinuclear regions of round spermatids (Figure 5A, right). To exclude the possibility that such LC3 expression pattern during spermatogenesis was due to inappropriate staining, the same immunofluorescence method was used to compare the LC3 signal between the $\operatorname{Atg} 7^{\text {Flox/Flox }}$ and the $\operatorname{Atg} 7^{--}$mouse embryonic fibroblasts (MEFs) during starvation. After $12 \mathrm{~h}$ of nutrient deprivation, the $\operatorname{Atg} 7^{\text {Flox }}$ ${ }^{\text {Flox }}$ MEFs displayed canonical autophagosome formation (Supplementary information, Figure S6A), while the LC3 signal still distributed evenly in $\operatorname{Atg} 7^{-1-}$ MEFs (Supplementary information, Figure S6A and S6B), suggesting that our staining protocol was appropriate and the antibody that we used was specific to LC3. We then used this method to study the relationship between LC3 and acrosome biogenesis. Further evaluation showed that LC3 was localized on proacrosomal vesicles derived from the Golgi apparatus, as indicated by its colocalization with a trans-Golgi network marker, TGN38 [11], at the early stages of spermiogenesis in $\operatorname{Atg} 7^{\text {Flox Flox }}$ mice (Figure 5B). By contrast, LC3 was no longer colocalized with TGN38 in Atg7-deficient spermatids (Figure 5B). Although LC3 still appeared as a punctate structure in Atg7-deficient spermatids, we observed LC3-I accumulation but not the membrane-associated form LC3-II accumulation in these cells (Figure 4D). It is likely that this type of LC3 punctate structure was not functional in mediating proacrosomal granule fusion or delivering the granules to the nucleus-associated acrosome. In this situation, the expansion of acrosome volume is affected, thus leading to a malformed acrosome. These results are consistent with the autolysosome origination hypothesis for the acrosome and suggest that autophagy is involved in the transportation/fusion of Golgi-derived proacrosomal vesicles to form the nucleus-associated acrosome.

Golgi-associated PDZ- and coiled-coil motif-containing protein $(G O P C)$ fails to be recruited to the acrosome in Atg7-deficient germ cells

To obtain a more comprehensive understanding of the role of autophagy in acrosome formation and how the germ cell-specific knockout of Atg7 leads to globozoospermia, we searched the literature for knockout mice with round-headed sperm and checked whether these knockouts involved any gene with a known relationship with autophagy. We found that mice with deficiency in GOPC had phenotypes similar to that of TNAP-Atg $7^{/-}$ mice, and GOPC is proposed to be involved in vesicle trafficking from the Golgi apparatus to the acrosome [19]. In addition, GOPC interacts with another autophagy-related protein, Beclin1 (Atg6), and these two proteins can synergize to induce autophagy [20]. We next confirmed that GOPC could be pulled down by Beclin1 and that this physical interaction was enhanced by starvation (Figure 6A). The partial colocalization of GOPC and Beclin1 in HeLa cells also supported a functional correlation between these two proteins (Figure 6B). We then examined the localization of GOPC, Beclin1 and sp56 (an acrosome marker that is a component of the acrosomal matrix) in spermatocytes by immunofluorescence [21]. In $\operatorname{Atg} 7^{\text {Flox Flox }}$ mice, Beclin1 was predominately colocalized with sp56, and GOPC partially overlapped with Beclin1 in the acrosome region of round spermatids. By contrast, although Beclin1 was still localized on the acrosome, GOPC failed to be recruited to the acrosome region in the spermatids of TNAP-Atg $7^{-1-}$ mice (Figure 6C). The percentage of GOPC that was colocalized with sp56 decreased to $11.23 \%$ compared with $93.69 \%$ in the $\operatorname{Atg} 7^{\text {Flox }}$ Flox mice (Figure 6D). It is likely that only when LC3 is conjugated to the membrane can GOPC be delivered to the acrosome. Our results suggest that Beclin1 and GOPC may work together in the same pathway during acrosome biogenesis and hint that the entire autophagy machinery rather than Atg7 alone is involved in vesicle trafficking from the Golgi apparatus to the acrosome.

Mice with autophagy/lysosome inhibitor injection mimics the phenotype of Atg7-knockout mice

To test whether the entire autophagy machinery is involved in acrosome biogenesis, $40 \mu \mathrm{l}$ of $5 \mathrm{mM}$ or 10 $\mathrm{mM}$ autophagic flux-specific inhibitor 3-methyladenine (3-MA) solution was directly injected into the testes of 6-week-old wild-type mice. The injection of 3-MA into the testis inhibited LC3 conjugation to the membrane (Figure 7A) and blocked the degradation of p62 (Figure $7 \mathrm{~B}$ and Supplementary information, Figure S7), suggesting that the autophagic flux was disrupted. After 2-4 weeks, the histology of the seminiferous tubules from the treated testes was compared with that of $\operatorname{Atg} 7^{\text {Flox/Flox }}$ testes. Similar to $T N A P-A \operatorname{tg} 7^{-/-}$male mice, some vacuoles were found in the seminiferous tubules after injection with 3-MA (Supplementary information, Figure S8B). Sp56 immunofluorescence showed that approximately $10 \%$ of the spermatids had multiacrosomal vesicles or aggregates in the cap phase (Figure 7C and 7D), and during the later maturation phase, up to $20 \%$ of the spermatids had abnormal acrosomes (Figure $7 \mathrm{C}$ and $7 \mathrm{E}$ ). The malformed acrosome was further confirmed by TEM. After treatment with 3-MA, some proacrosomal vesicles (arrows, upper panel) failed to be transported to the center of the acrosome in the Golgi phase (Supplementary information, Figure S9). In the cap phase, the Golgi apparatus was still close to the proacrosomal structure, with 
A
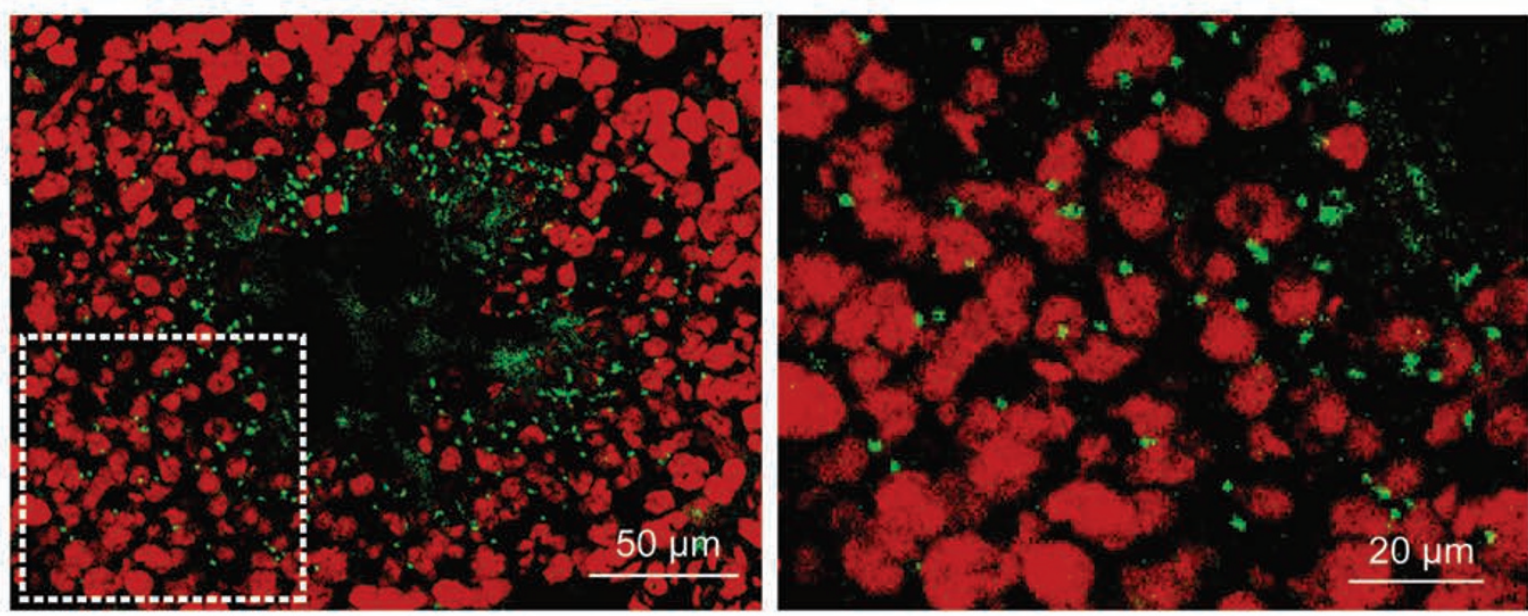

B
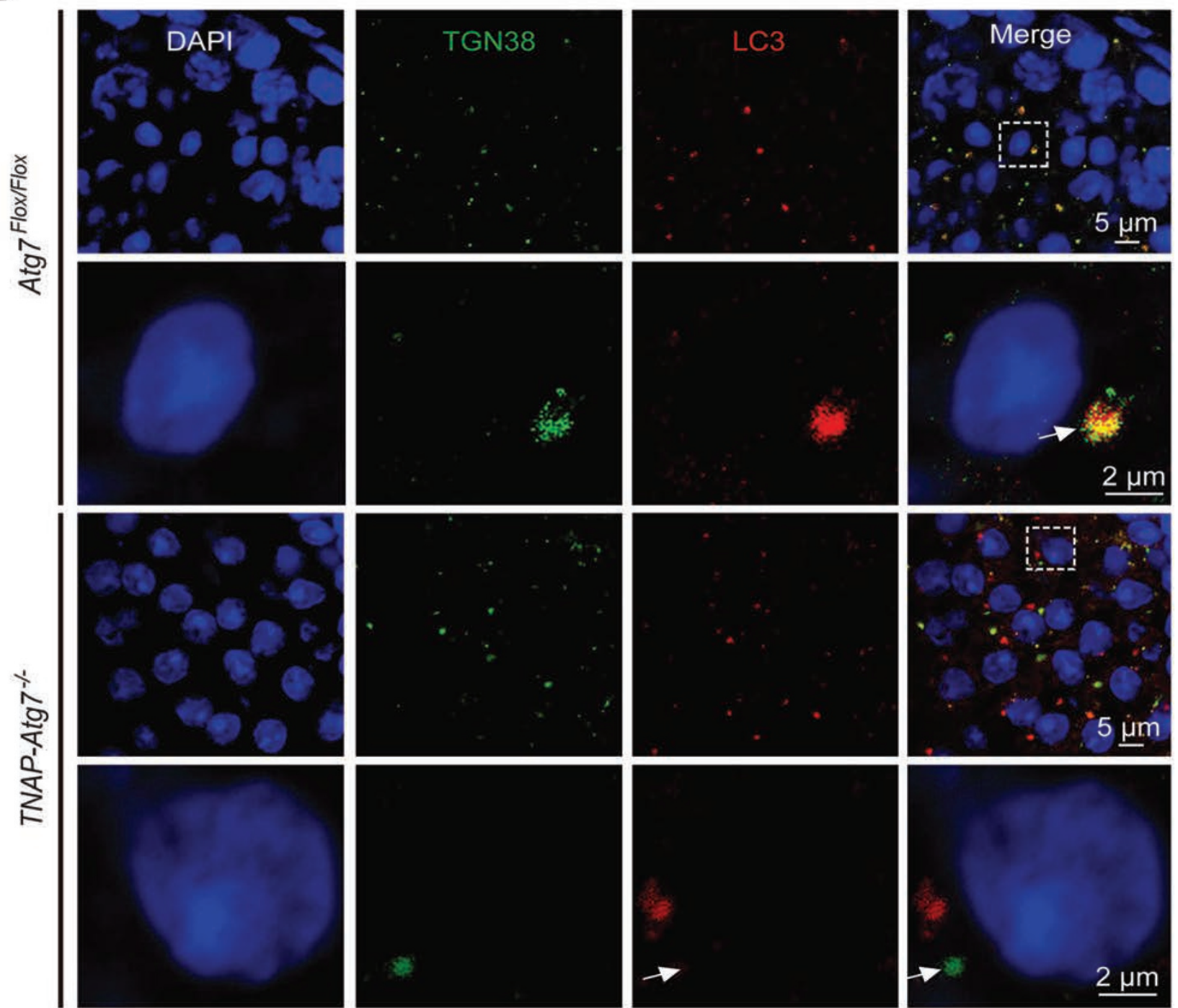

Figure 5 Atg7 deficiency in germ cells disrupts the colocalization of LC3 and Golgi-derived vesicles. (A) Immunodetection of LC3 (green) in the seminiferous tubules of $A \operatorname{tg} 7^{\text {Flox/Flox }}$ mice. The nucleus (red) was counterstained with PI. (B) TGN38 (green)

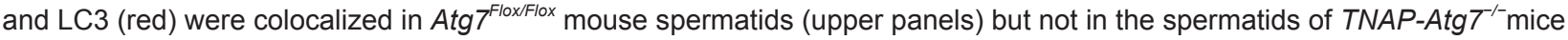
(lower panels). 
A

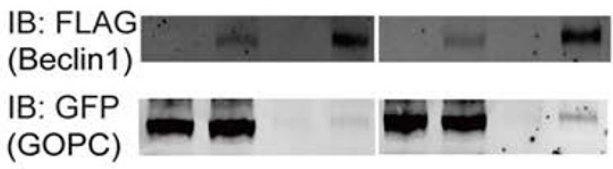

C
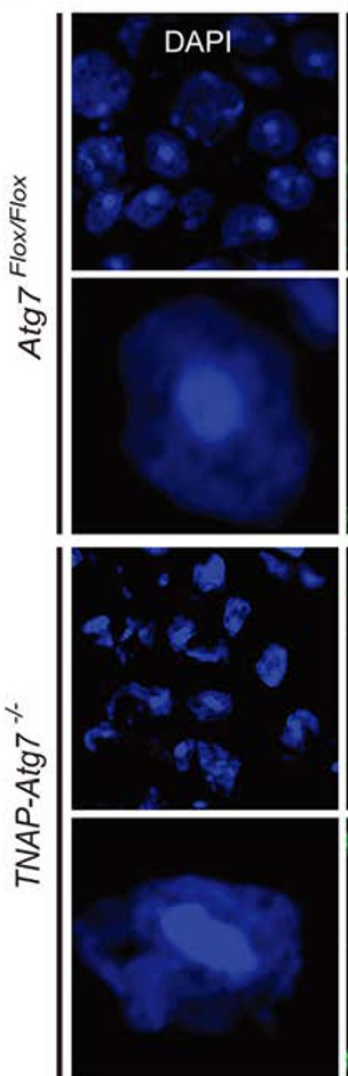

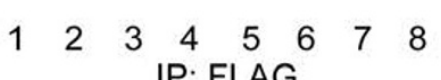

IP: FLAG
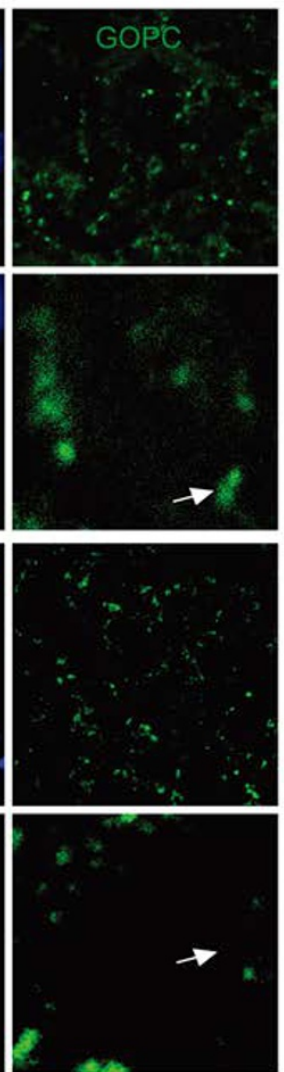

B
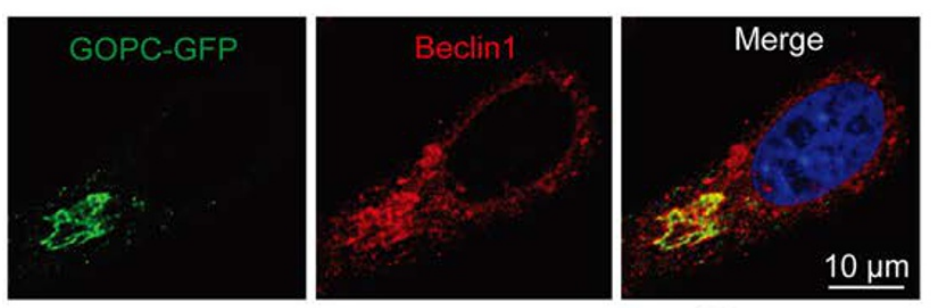

D
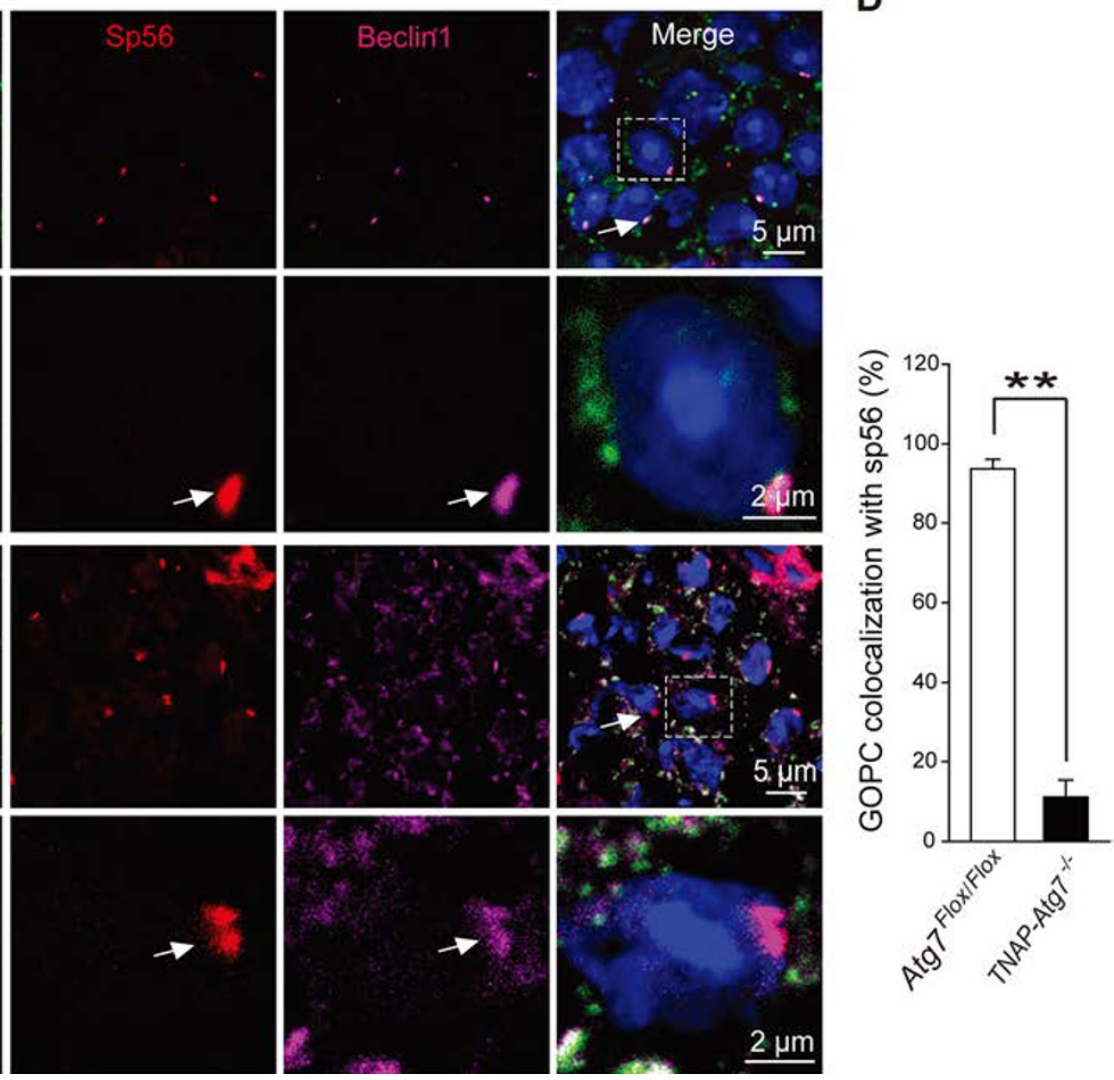

Figure 6 GOPC fails to be recruited to the acrosome in the spermatids of TNAP-Atg $7^{-/}$mice. (A) Co-immunoprecipitation analysis of the GOPC-GFP and FLAG-Beclin1 interactions. In 293T cells, FLAG-Beclin1 immunoprecipitated with GOPC-GFP (lane 4), and this interaction was enhanced by starvation (lane 8). A negative control group was transfected with GFP-GOPC and FLAG-pRK (lane 3, lane 7). Lanes 1 and 5 and lanes 2 and 6 are inputs for lanes 3 and 7 and lanes 4 and 8 , respectively. (B) Partial colocalization of GOPC (green) and Beclin1 (red) in HeLa cells. (C) GOPC (green), sp56 (red), and Beclin1 (pink) were co-localized in the spermatids of $A \operatorname{tg} 7^{\text {Flox/Flox }}$ mice (upper panels). An arrow indicates this co-localization. Sp56 (red) and Beclin1 (pink) were still colocalized in TNAP-Atg $7^{-/}$mouse spermatocytes, but GOPC (green) was not recruited to the acrosome (lower panels). (D) Statistical analysis of GOPC and sp56 colocalization in Atg $7^{\text {Flox/Flox }}$ and TNAP-Atg $7^{-/-}$mice. TNAP$\operatorname{Atg} 7^{-/}, 11.23 \pm 4.25 \% ; \operatorname{Atg} 7^{\text {Flox/Flox }}, 93.69 \pm 2.44 \%$.

some vesicles (arrows, middle panel) accumulated in the concave region of the nuclear surface (Supplementary information, Figure S9). These early-phase defects finally resulted in malformed acrosomes in the maturation phase (Supplementary information, Figure S9). After injection with $10 \mathrm{mM}$ 3-MA for 4 weeks, the morphology of sperm from the cauda epididymis was then evaluated. Approximately $30 \%$ of the total spermatozoa had irreg- ularly shaped round heads (Figure 8A), and had malformed acrosomes as detected by sp56 staining (Figure $8 \mathrm{~B}$ and $8 \mathrm{C}$ ). These results are similar to those in germ cell-specific Atg7-knockout mice and suggest that the whole autophagy machinery might be involved in acrosome biogenesis.

A direct prediction of the autolysosome origination hypothesis is that the autolysosome should also be in- 
A

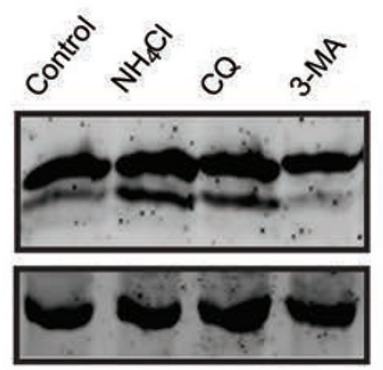

B

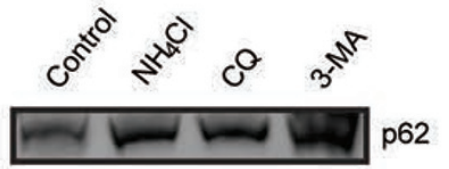

D

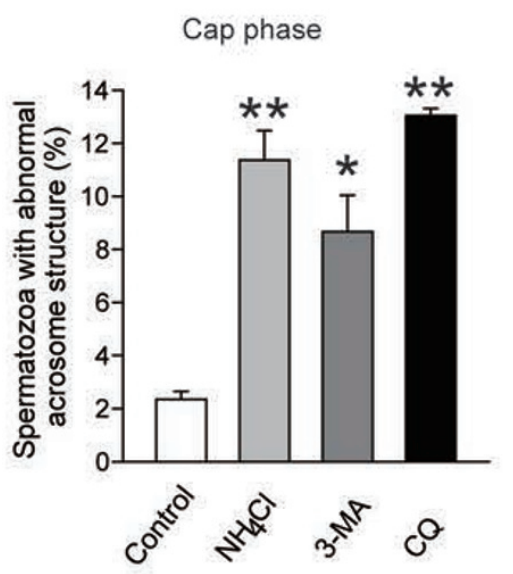

E

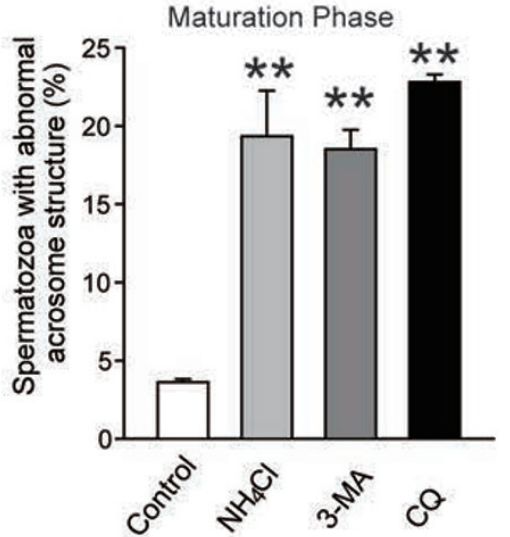

C

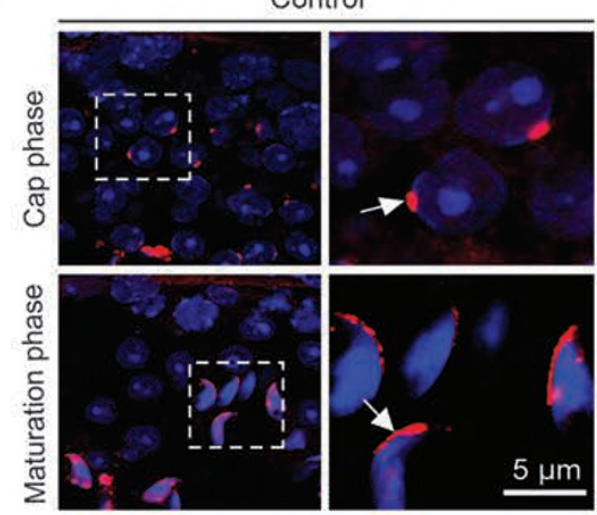

3-MA
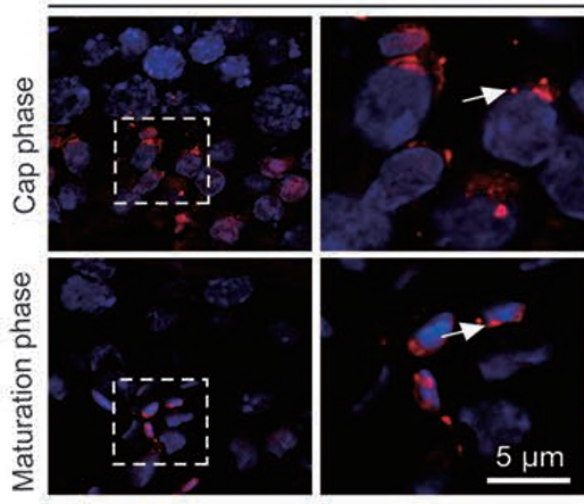

F
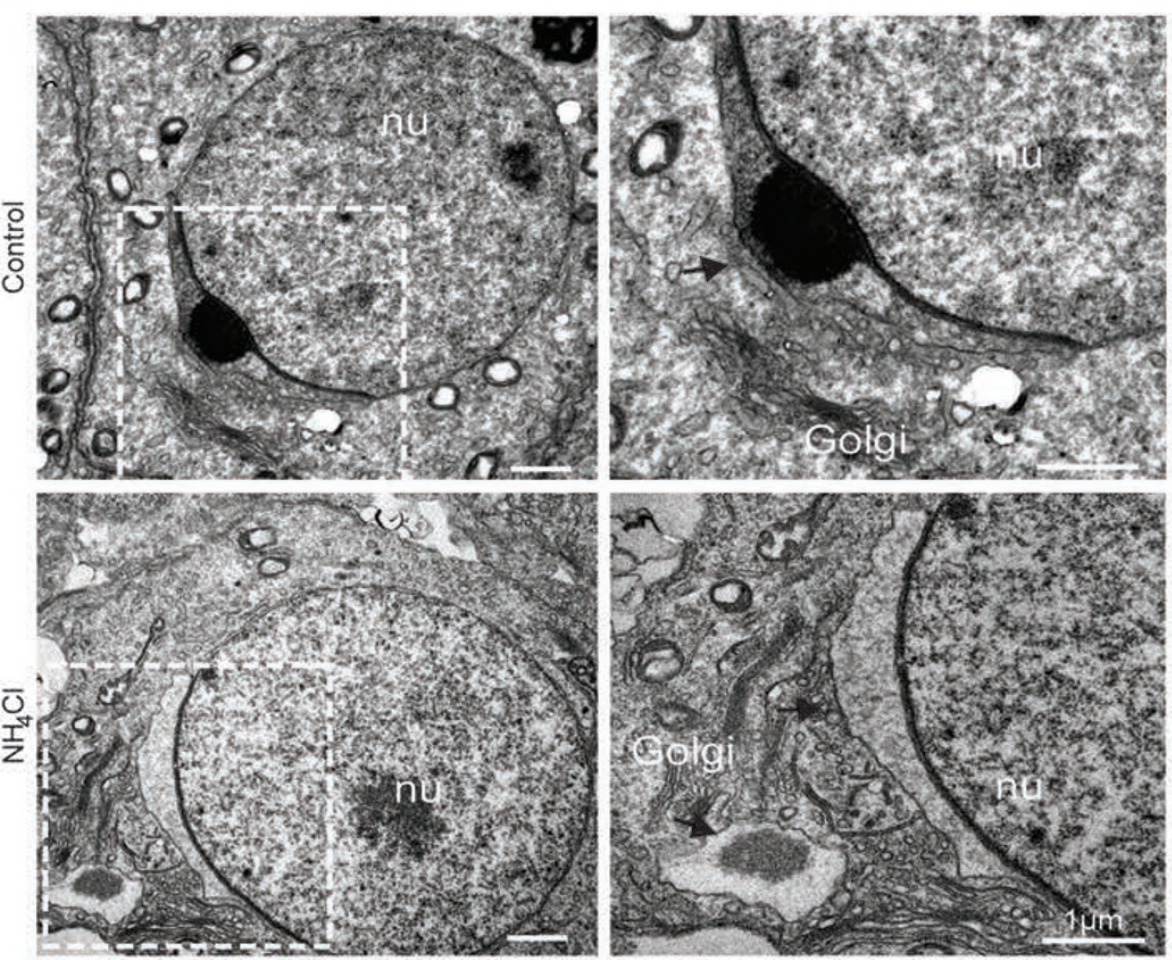
Figure 7 Acrosome biogenesis defects caused by injection of autophagy/lysosome inhibitors. (A) Western blotting analysis of LC3 in the extracts of testis from mice injected with physiological saline (control), ammonium chloride $\left(\mathrm{NH}_{4} \mathrm{Cl}\right)$, chloroquine (CQ) or 3-MA. There was an increase in LC3-II level in $\mathrm{NH}_{4} \mathrm{Cl}$ - and $\mathrm{CQ}$-treated testis but a decrease in the 3-MA-treated group compared with the control. (B) Accumulation of p62 was found in the testis after treatment with $\mathrm{NH}_{4} \mathrm{Cl}, \mathrm{CQ}$ or $3-\mathrm{MA}$. Actin was used as a loading control. (C) Sp56 immunofluorescence in the control and inhibitor-treated testis. After injection with any of the three inhibitors for 1-2 weeks, proacrosome vesicles or unfused acrosomes (arrows) were found in the cap phase of spermatocytes, and spermatids with abnormal acrosomes were found in the maturation phase. Boxed areas are further magnified on the right. Bar, $5 \mu \mathrm{m}$. (D, E) Quantification of abnormal acrosomes in the cap phase and maturation phase of $\mathbf{C}$. Cap phase: control, $2.34 \pm 0.30 \%$; $\mathrm{NH}_{4} \mathrm{Cl}, 11.35 \pm 1.12 \%$; $\mathrm{CQ}, 13.04 \pm 0.27 \%$; 3-MA, $8.66 \pm 1.37 \%$. Maturation phase: control, $3.60 \pm 0.21 \% ; \mathrm{NH}_{4} \mathrm{Cl}, 19.33 \pm 0.49 \% ; \mathrm{CQ}, 22.79 \pm 2.91 \%$; 3-MA, $18.49 \pm 1.25 \%$. (F) TEM analysis of spermatocytes from $\mathrm{NH}_{4} \mathrm{Cl}$-treated mouse testis. In the control group, the proacrosomal structure was typical, with an acrosomal granule in the center (arrow) and a cap along the nucleus, whereas in the $\mathrm{NH}_{4} \mathrm{Cl}$-treated testis, the acrosomal granule was not successfully recruited to the nucleus-associated acrosome (arrow). nu, nucleus; Golgi, Golgi apparatus. Bar indicates $1 \mu \mathrm{m}$.

volved in acrosome biogenesis. To test whether the autolysosome participates in the acrosome biogenesis, two acidification inhibitors (which can inhibit the function of the lysosome/autolysosome), chloroquine (CQ) and ammonium chloride, were injected separately into the testes of wild-type mice. The injection of either of these inhibitors caused LC3-II accumulation (Figure 7A) and p62 stabilization (Figure 7B and Supplementary information, Figure S7), suggesting that the degradation function of autolysosome was blocked in the injected testis. Most importantly, the injection of either inhibitor resulted in a similar phenotype to that of the TNAP-Atg $7^{-1}$ mice (Figure 7C-7F and Supplementary information, Figures S8S10). First, vacuolization occurred in some seminiferous tubules after injection with either CQ or ammonium chloride for 2-4 weeks (Supplementary information, Figure S8A and S8C). Second, many proacrosomal vesicles or unfused acrosomes were found in the early phase during acrosome biogenesis (Figure 7C and 7D). The detachment of those proacrosomal vesicles from the nucleus was further confirmed by TEM (Figure 7F and Supplementary information, Figure S10). Consistent with those results, some abnormal acrosomes were found during the maturation phase of acrosome biogenesis in the injected seminiferous tubules (Figure 7C, 7E and Supplementary information, Figure S10). Third, many spermatozoa from the epididymis of inhibitor-injected mice showed round-headed morphology (Figure 8A). Finally, sp56 immunofluorescence of spermatozoa revealed that injection of either inhibitors resulted in the malformation of many acrosomes (Figure 8B, 8D and 8E). Consistent with the autolysosome origination hypothesis, these results suggest that the autolysosome is also involved in acrosome biogenesis.

\section{Discussion}

The acrosome is a unique organelle that is formed by the fusion of Golgi-derived vesicles [2]. The mamma- lian acrosome contains many enzymes associated with lysosomes in somatic cells, and both acrosomes and lysosomes share a common feature, which is their low internal acidic $\mathrm{pH}$ [22]. According to these similarities, the acrosome has been postulated to be a modified lysosome [4]. Components of the endocytic machinery, such as Afaf [14], SH3P13 [23], SPE-39 [24], UBPy [25], RasGRF1 [26], and Vps54 [27, 28], are involved in the biogenesis of the acrosome [2]. This evidence strongly supports the notion that the acrosome is a novel LRO. Although restricted to certain specialized cell types, LROs represent a family of membrane-enclosed organelles that share many properties with lysosomes.

To explain how lysosomes are modified to make a LRO such as the acrosome, we proposed an autolysosome origination hypothesis: the acrosome originates from an autolysosome rather than a mere lysosome. As autophagy is essential to the biogenesis of autolysosomes, it should also be essential to the biogenesis of acrosomes. In this study, we validated this prediction through the germ cell-specific ablation of Atg7. After Atg7 depletion, the acrosome biogenesis was affected from the very early stage, which resulted in round-headed sperm, a phenotype similar to globozoospermia in human patients. In addition, an autophagy inhibitor (3$\mathrm{MA}$ ) or autolysosome inhibitors $\left(\mathrm{CQ}\right.$ and $\mathrm{NH}_{4} \mathrm{Cl}$ ) caused a similar phenotype to germ cell-specific Atg7-knockout mice. These findings support our hypothesis that the acrosome is originated from the modification of autolysosome biogenesis system during evolution, and that at least two major autolysosome biogenesis contributors, the endocytic machinery and autophagic machinery [29], are evolutionarily conserved during the modification process. We speculate that this mechanism is conserved in all organisms that have acrosomes on their sperm.

Ten genes have been found to be associated with globozoospermia, including Csnk2a2 [30], Hrb [3], Gopc [19], Gba2 [31], Zpbp1 [32], Pick1 [11], Vps54 [27], Hsp90b1 [33], Spacal [34] and Dpy19l2 [35]. Among 

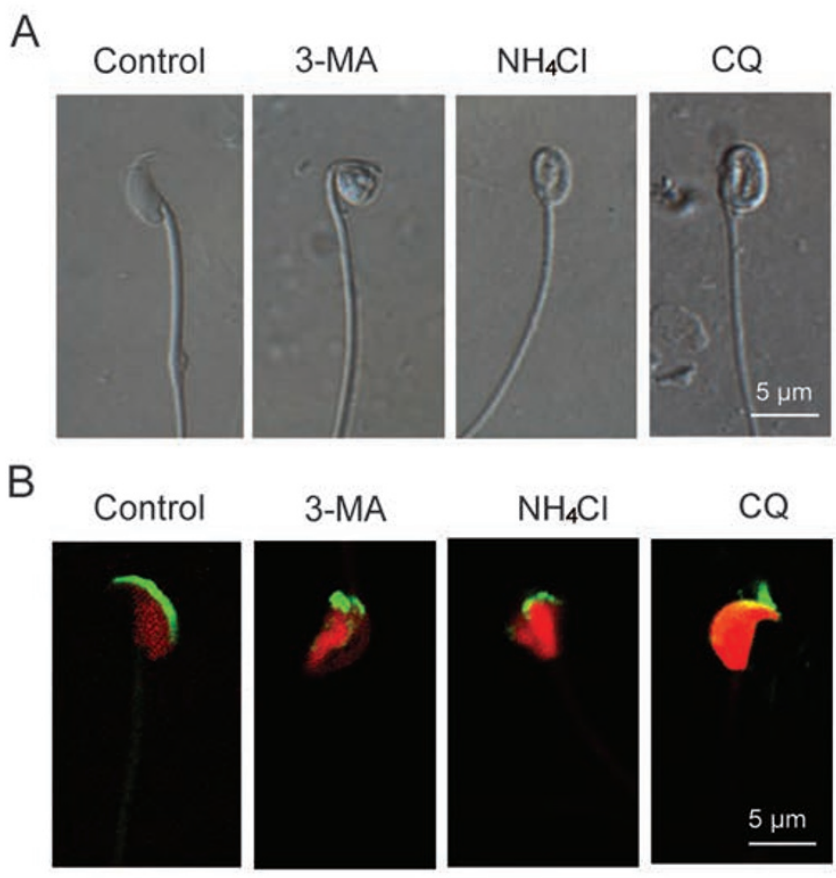
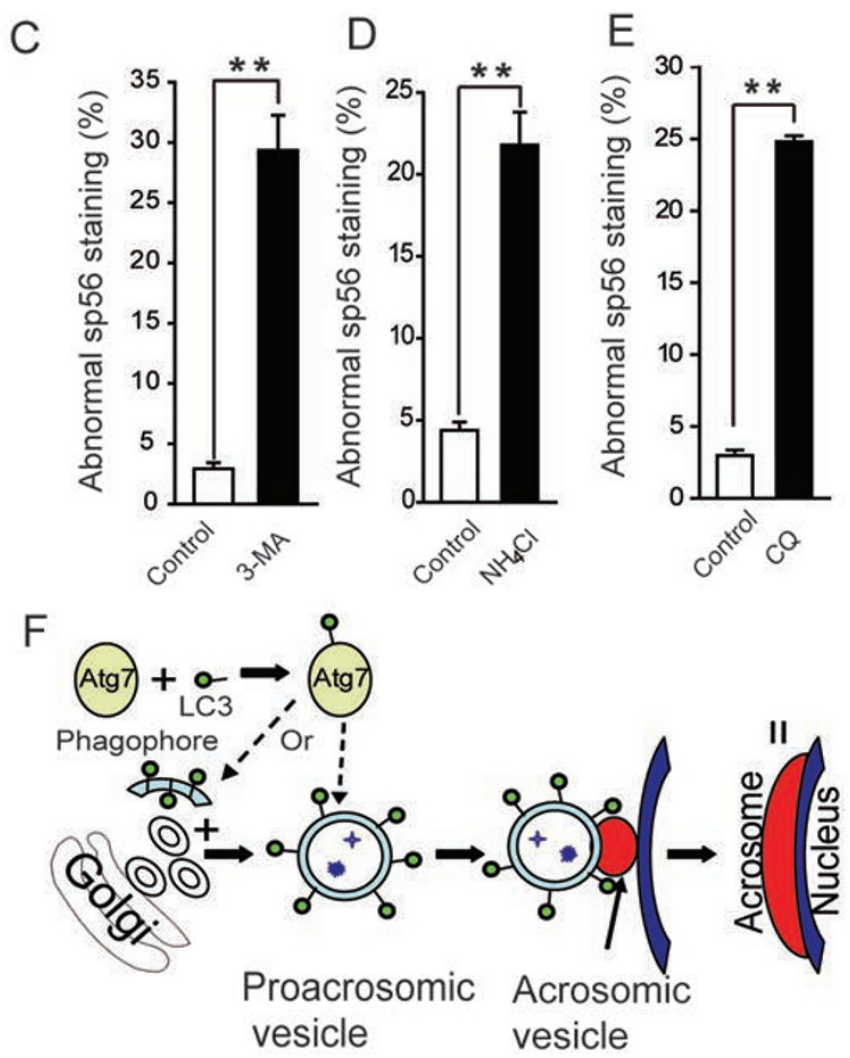

\section{vesicle vesicle}

Figure 8 Autophagy/lysosome inhibitor injection into the testes results in malformed acrosomes. (A) Representative round-headed spermatozoa from the epididymis of 3-MA-, CQ- or $\mathrm{NH}_{4} \mathrm{Cl}$-injected mice. (B) Representative sp56 immunofluorescence to show malformed acrosomes after 3-MA, $\mathrm{NH}_{4} \mathrm{Cl}$ or $\mathrm{CQ}$ injection for 4 weeks. Bar, $5 \mu \mathrm{m}$. (C-E) Statistical analysis of sp56 immunofluorescence. $29.33 \pm 0.04 \%$ of the total spermatozoa had irregular acrosomes after injection with $10 \mathrm{mM}$ 3-MA for 4 weeks, while only $2.93 \pm 0.01 \%$ malformed acrosomes were found on the control spermatozoa (C). $21.79 \pm 0.02 \%$ vs $4.38 \pm 0.01 \%$ for $\mathrm{NH}_{4} \mathrm{Cl}$ injection (D). $24.82 \pm 0.02 \%$ vs $2.97 \pm 0.01 \%$ for $\mathrm{CQ}$ injection (E). (F) A proposed model for the role of autophagy in acrosome biogenesis. Green dots indicate LC3.

them, Hrb [3], GOPC [19], PICK1 [11] and SPACA1 [34] control Golgi-derived vesicle fusion, which is necessary for acrosome formation. We found that GOPC partially colocalized with sp56 on the acrosome during spermatogenesis but failed to be recruited to the acrosome in Atg7-deficient spermatids, suggesting that Atg7 partially regulates GOPC and that both of them are involved in Golgi-derived vesicle fusion and transport to the preacrosome.

The function of Atg7 in acrosome biogenesis may be similar to its role in autophagy induction. During the autophagy induction process, LC3 is activated by Atg7, transferred to another E2-like enzyme (Atg3), and conjugated to the lipid/membrane, and then it finally functions as a scaffold to drive membrane expansion and vesicle completion. LC3-lipid conjugation is a reversible process. LC3 residing on the outer face of the vesicle can be liberated by Atg 4 and used in another conjugation reaction, whereas LC3 on the inner surface is eventually degraded in autolysosomes [6-8]. Consistent with this finding, we found that LC3 is only colocalized with the trans-Golgi network marker TGN38 (Figure 5B) but not the acrosome maker sp56 (Supplementary information, Figure S11) in round spermatids. These results suggest that membrane-associated LC3 might participate in the fusion of Golgi apparatus-derived proacrosomal vesicles and/or their transportation to the acrosome and that once fused with the acrosome, LC3 is either recycled or degraded. We speculate that LC3 could not be conjugated to the membrane after Atg7 inactivation and thus failed to colocalize with TGN38, which caused the accumulation of Golgi apparatus-derived proacrosomal vesicles in the concave region near the trans-Golgi stacks (Figure $3 \mathrm{~F}$ ). This accumulation greatly delayed the increase of acrosome volume in the later stages and finally resulted in defective acrosome formation. 
Actually, Golgi-derived vesicles also play an important role during autophagy induction. Our results (Figure 6A), together with others [20], show that GOPC interacts with another autophagy-related protein, Beclin1 (Atg6), mainly at the trans-Golgi network (TGN) during autophagy induction. As a transmembrane protein, Atg9 is located in the TGN in mammalian cells [36], and Atg16L is recruited to the Golgi complex by a small GTPase, Rab33B [37]. In addition, the Golgi complex plays a crucial role in supplying the lipid bilayers that are necessary for the biogenesis of double-membrane autophagosomes in yeast [38], and TGN membranes are required for autophagosome formation in mammalian cells [39]. Thus, it is possible that during the biogenesis of either autolysosomes or acrosomes, LC3 is activated by Atg7 and then transferred to the Golgi-derived vesicles either directly or mediated by phagophore-like structures, finally inducing the fusion of those vesicles with each other or their transportation to the nucleus-associated acrosome (Figure $8 \mathrm{~F})$. We propose that acrosomes and autolysosomes share common mechanisms of biogenesis.

Although those two organelles share similar biogenesis mechanisms, it is likely that Atg7 plays non-autophagic roles during acrosome biogenesis. In addition to the cellular degradative pathway, autophagy plays an unexpectedly broad biogenic role in protein trafficking and secretion [37]. Atg16L and Atg5 are involved in the exocytosis of granules containing antimicrobial peptides from Paneth cells [40]. Atg5, Atg7, Atg4B and LC3 participate in the polarized secretion of lysosomal contents in osteoclasts [41]. Atg5 and Atg4B are involved in the secretion of otoconins by vestibular sensory cells of the inner ear [42]. Beclin1 and LC3-A have been implicated in the maturation of a specialized LRO, the melanosome [43]. As a novel LRO, the acrosome is regarded as a secretory lysosome not only because of its internal acid $\mathrm{pH}$ but also because it contains many enzymes associated with lysosomes in somatic cells [22]. Upon fertilization, the acrosome reaction initiates, and the membrane surrounding the acrosome bursts and exposes the contents of the acrosome to remove cumulus cells or break down the outer membrane of the oocyte to fertilize it [44]. This process is similar to the above-mentioned secretory pathways. We found that Atg7 and possibly the entire autophagy machinery are required for both acrosome biogenesis and the acrosome reaction, suggesting a non-degradative role of autophagy in acrosome biogenesis.

In addition to the defect in acrosome biogenesis, we observed malformation of the nucleus in TNAP-Atg $7^{1-}$ mouse spermatids. We are unsure whether this morphological defect is caused by Atg7 deficiency directly or whether it is a secondary effect of the defect in acroso- mal biogenesis. However, this is a common phenotype reminiscent of that described in human globozoospermia, with the signature characteristics of round-headed spermatozoa and malformed acrosomes [31], and the relationship between acrosome biogenesis and nuclear architecture during spermiogenesis is currently unclear.

A decrease in total sperm number and testis weight appears to be a common phenotype for a variety of genetic defects perturbing the normal processes of mouse spermiogenesis [3]. In the case of the germ cell-specific knockout of Atg7, many germ cells died, resulting in large vacuoles in the tubule lumens of testes. This defect appears to be due to the cell cycle and survival regulatory functions of $\operatorname{Atg} 7 . \operatorname{Atg} 7$ can bind to the tumor suppressor p53 in an E1-like enzymatic activity-independent manner to regulate the transcription of the gene encoding the cell cycle inhibitor p21-CDKN1A. Once Atg7 was knocked out, cells failed to properly induce p21-CDKN1A expression, resulting in augmented DNA damage with increased p53-dependent apoptosis. The cell cycle-specific role of Atg7 neither requires its E1-like enzymatic activity nor exists in other autophagy-related genes such as $\operatorname{Atg} 5$ or $\operatorname{Atg} 6$ [35]. Thus, it is most likely that the cell death in the tubule lumens of the testes is dependent on the cell cycle regulatory function of Atg7 rather than its E1-like enzymatic activity.

Because our observations are based on the deletion of a single autophagy-related gene, we cannot rule out the possibility that the acrosome biogenesis defect is due to the specific role of Atg7. However, based on the inhibitor injection experiments, we speculate that the knockout of most of the autophagy machinery genes will cause an acrosome biogenesis defect, although slightly different phenotypes might exist for germ cell-specific knockout of different autophagy-related genes.

In conclusion, we have validated the autolysosome origination hypothesis for the acrosome by providing genetic evidence that Atg7 and possibly the entire autophagy machinery are essential to acrosome biogenesis during spermiogenesis. Atg7 and most likely the entire autophagy molecular machinery participate in the fusion and transportation of proacrosomal vesicles derived from the Golgi apparatus to the acrosome, which is similar to their roles in autophagy induction. This mechanism may be applied to the biogenesis of other LROs, such as lytic granules, major histocompatibility complex class II compartments and platelet-dense granules.

\section{Materials and Methods}

\section{Animals}

The Atg $7^{\text {Flox/Flox }}$ mouse strain (RBRC02759) [9] was purchased 
from the RIKEN BioResource Center. $\operatorname{Atg} 7^{\text {Flox/Flox }} ;$ TNAP-Cre mice were bred from $A \operatorname{tg} 7^{\text {Flox/Flox }}$ mice and TNAP-Cre mice [10], which were purchased from the Jackson Laboratory (008569). Atg $7^{\text {Flox }}$ ${ }^{F l o x}$; Tamoxifen-cre mice were generated from the breeding of Atg$7^{\text {Flox/Flox }}$ mice and Tamoxifen-cre mice [45], which were purchased from Jackson laboratory (004682). All animal experiments were approved by the Animal Research Panel of the Committee on Research Practice of the University of Chinese Academy of Sciences.

\section{Antibodies}

Rabbit anti-LC3 polyclonal antibody (ab58610), sheep anti-Beclin1 polyclonal antibody (ab62108), rabbit anti-SYCP3 polyclonal antibody (ab15093) and rabbit anti-GOPC antibody (ab37036) were all purchased from Abcam (Cambridge, UK). Mouse anti-sp56 (55101) antibody was purchased from QED bioscience (San Diego, USA). Rabbit anti-mTOR monoclonal antibody (2893), rabbit anti-phospho-mTOR antibody (5536), rabbit anti-SQSTM1/ p62 polyclonal antibody (5114), rabbit anti-phospho-p70S6 Kinase monoclonal antibody (9234) and rabbit anti-phospho-AMPK monoclonal antibody (2535) were all purchased from Cell Signaling Technology (Massachusetts, USA). Mouse anti-ATG7 monoclonal antibody (SAB4200304) for western blot, rabbit anti-LC3B polyclonal antibody (L7543) for western blot, and rabbit anti-FLAG polyclonal antibody (F7425) were purchased from Sigma-Aldrich (St. Louis, USA). Sheep anti-TGN38 polyclonal antibody (NB110-60519) was purchased from Novus biologicals (Colorado, USA). Mouse anti-actin antibody (KM9001) was purchased from Sungene Biotech (China). Mouse anti-GFP monoclonal antibody (M20004) was purchased from Abmart (China). Afaf was made as previously described [14]. Goat anti-rabbit FITC, goat anti-mouse FITC, goat anti-rabbit TRITC, and goat anti-mouse TRITC-conjugated secondary antibodies as well as horseradish peroxidase (HRP)-conjugated secondary antibodies were purchased from Zhong Shan Jin Qiao (China). Donkey anti-rabbit Cy5 and donkey anti-sheep FITC-conjugated secondary antibodies were purchased from Jackson ImmunoResearch. Alexa Fluor 680-conjugated goat anti-mouse and Alexa Fluor 800-conjugated goat anti-rabbit secondary antibodies for western blotting were purchased from Invitrogen (California, USA).

\section{Assessment of the fertility of ATG7-deficient mice}

Males of different genotypes (8-9 weeks) were used for the breeding assay. Each male mouse was caged with two wild-type CD1 females (7-8 weeks), and their vaginal plugs were checked every morning. The number of pups in each cage was counted within a week of birth. Each male underwent four cycles of the above breeding assay.

\section{Epididymal sperm count}

The cauda epididymis was dissected from adult mice. Sperm was squeezed out from the cauda epididymis and incubated for 30 min at $37{ }^{\circ} \mathrm{C}$ under $5 \% \mathrm{CO}_{2}$. The incubated sperm medium was then diluted 1:500 and transferred to a hemocytometer for counting. Non-fixed sperm were spread on precoated slides for morphological observation or immunostaining.

\section{Immunoblot and co-immunoprecipitation}

Tissue extracts were prepared using a Dounce homogenizer in cold RIPA buffer (25 mM Tris-HCl, pH 7.6, $150 \mathrm{mM} \mathrm{NaCl,} \mathrm{1 \%}$ NP-40, $1 \%$ sodium deoxycholate, $0.1 \%$ sodium dodecyl sulfate) supplemented with $1 \mathrm{mM}$ phenylmethylsulfonyl fluoride and a protein inhibitor cocktail (Roche). The homogenates were centrifuged at $12000 \mathrm{rpm}$ for $15 \mathrm{~min}$, and protein concentrations were determined using the Bio-Rad protein assay. Protein lysates (25 $\mu \mathrm{g})$ were separated in SDS-PAGE and electrotransferred to a nitrocellulose membrane. The membrane was scanned using the ODYSSEY Sa Infrared Imaging System (LI-COR Biosciences, USA).

For immunoprecipitation, FLAG-beads (A2220, Sigma) were washed with sterile, double-distilled water and then washed with cold RIPA buffer twice. Cell extracts were then added to the FLAG beads and rotated at $4{ }^{\circ} \mathrm{C}$ for $3 \mathrm{~h}$. The beads were then washed with cold RIPA buffer and mixed with loading buffer. After incubation at $37{ }^{\circ} \mathrm{C}$ for $15 \mathrm{~min}$, the beads were centrifuged, and the supernatants were loaded onto the gel as samples.

\section{TEM}

Adult testes were fixed with $2.5 \%$ glutaraldehyde in $0.2 \mathrm{M}$ cacodylate buffer overnight. After washing in $0.2 \mathrm{M} \mathrm{PB}$, the tissue was cut into small pieces, approximately $1 \mathrm{~mm}^{3}$, and immersed in $1 \% \mathrm{OsO}_{4}$ in $0.2 \mathrm{M}$ cacodylate buffer for $2 \mathrm{~h}$ at $4{ }^{\circ} \mathrm{C}$. Then, the samples were dehydrated through a graded ethanol series and embedded in resin. Ultrathin sections were cut on an ultramicrotome, stained with uranyl acetate and lead citrate and then observed using a JEM-1400 transmission electron microscope.

\section{Immunofluorescence}

Adult male C57BL/6 mice were killed according to the guidelines of the Ethics Committee of the Institute of Zoology, Chinese Academy of Sciences. The tissue was immediately embedded in optimum cutting temperature compound (OCT, Tissue-Tek) and cut into $8-\mu \mathrm{m}$ sections using a microtome-cryostat (Leica CM1950). Frozen testis sections or cultured MEFs were fixed with $4 \%$ paraformaldehyde (PFA) for $15 \mathrm{~min}$ and washed in PBS 3 times ( $\mathrm{pH} 7.4$ ). Then, after blocking with $5 \%$ bovine serum albumin (BSA, Sigma) for $30 \mathrm{~min}$, slides were incubated with primary antibody in $1 \%$ BSA at $4{ }^{\circ} \mathrm{C}$ overnight. After washing with PBS, the sample was incubated with FITC- or TRITC-conjugated secondary antibody diluted with PBS for $1 \mathrm{~h}$ at $37^{\circ} \mathrm{C}$. Next, the slides were washed in PBS, and nuclei were stained with propidium iodide (PI) or 4',6-diamidino-2-phenylindole (DAPI). Images were taken immediately using a LSM 780/710 microscope (Zeiss). For sperm immunofluorescence, the spermatozoa were washed with PBS 3 times, plated onto 3-aminopropyl-triethoxysilane-coated coverslips, fixed, and stained as detailed above.

\section{Immunohistochemistry}

Paraffin sections were fixed with 4\% PFA and rinsed in PBS three times ( $\mathrm{pH}$ 7.4). Then, sections were boiled for $15 \mathrm{~min}$ in sodium citrate buffer for antigen retrieval. Next, $3 \% \mathrm{H}_{2} \mathrm{O}_{2}$ was added to the sections to eliminate internal peroxidase activity. After blocking with 5\% BSA, each section was incubated with the primary antibody at $4{ }^{\circ} \mathrm{C}$ overnight, followed by staining with the HRP-conjugated secondary antibody. Negative controls were prepared without the primary antibody. Finally, the sections were stained with 3, 3'-diaminobenzidine (DAB), and the nuclei were stained with hematoxylin. Images were taken using a Nikon $80 \mathrm{i}$ inverted microscope with a CCD.

\section{Acrosome reaction analysis}

Spermatozoa were processed as previously described [46] 
and images were taken immediately under microscope. Briefly, spermatozoa were dissected from the epididymis, incubated in the human tubal fluid for $2 \mathrm{~h}$ at $37^{\circ} \mathrm{C}$, then washed with glucose and treated with streptolysin O (SLO) for membrane permeating. Next, spermatozoa were incubated with or without A23187 and then smeared to the glass slide. After the fixation with methanol, spermatozoa were stained with PSA-FITC.

\section{Generation of $A \operatorname{tg} 7^{-/-}$MEFs and cell starvation}

$\operatorname{Atg} 7^{\text {Flox/Flox }}$;Tamoxifen-cre mice were generated from the breeding of $\operatorname{Atg} 7^{\text {Flox/Flox }}$ mice with Tamoxifen-cre mice. When the female mice showed plugs and were pregnant on day 12, they were killed and the embryos were isolated as previously described [47]. For the knockout of Atg7 in the MEFs, 4-OH-tamoxifen (H7904, Sigma-Aldrich) was added to the medium at a final concentration of $0.1 \mathrm{mM}$ to induce the gene knockout for at least 3 days. Cells were incubated in $37 \mathrm{C}$ with $5 \% \mathrm{CO}_{2}$ in air. Cells were starved by incubating the cells in HBSS with calcium and magnesium ions after three separate washes with PBS. Knockout efficiency was confirmed by western blotting.

\section{Autophagy/lysosome inhibitor treatment}

Inhibitor solutions were injected into mouse testes using a previously described method $[48,49]$ with slight modification. Briefly, 6-week-old wild-type CD1 male mice were anaesthetized with avertin, which was administered by an intraperitoneal injection (T48402, Sigma), and $40 \mu 1$ of autophagy/lysosome inhibitor solutions were slowly injected under the tunica vaginalis of the testes with a needle attached to a $50 \mu 1$ micro-injector at a depth of 5-6 $\mathrm{mm}$ under the tunica albuginea. All three inhibitors were dissolved in $0.9 \% \mathrm{NaCl}$ to make a final working solution. The concentrations were as follows: 3-MA (M9281, Sigma), $5 \mathrm{mM}$ as a low concentration and $10 \mathrm{mM}$ as a high concentration; CQ (C6628, Sigma), $200 \mu \mathrm{M}$ as a low concentration and $300 \mu \mathrm{M}$ as a high concentration; $\mathrm{NH}_{4} \mathrm{Cl}$ (A9434, Sigma), $2 \mathrm{mM}$ as a low concentration and 4 $\mathrm{mM}$ as a high concentration. Physiological saline was injected as a control. After injection of the testes, mice were fostered for another 2, 3 or 4 weeks. Testes were then dissected and fixed for normal histological analysis; spermatozoa from the epididymis were taken to examine their morphology and acrosome structure by sp56 immunofluorescence.

\section{ICSI}

Eight- to twelve-week-old CD1 and B6D2F1 mice (C57BL/6 $\times$ $\mathrm{DBA} / 2$ ) were used to prepare mature oocyte donors. CD1 females that were mated with vasectomized males of the same strain were surrogates. Spermatozoa were released from the cauda epididymis with forceps compressing [50] and suspended in M2 medium. ICSI was then carried out as described previously [51-53] with some modifications. Briefly, $10 \mu 1$ of sperm suspension was added to $1 \mathrm{ml} \mathrm{M} 2$ medium supplemented with $5 \mu \mathrm{g} / \mathrm{ml}$ of cytochalasin $\mathrm{B}$, and 15-20 mature oocytes were placed in the M2 medium for 5 min. Then, using a Piezo-driven pipette, we separated the spermatozoon head from its tail and injected one head into each oocyte. After injection, the microinjected embryos were transferred into M16 medium and cultured at $37.5{ }^{\circ} \mathrm{C}$, under $5 \% \mathrm{CO}_{2}$ in air. Twocell embryos were transferred to each oviduct of CD1 surrogate females on day 1 of pseudopregnancy. Full-term pups derived from ICSI embryos were obtained through natural labor or caesarean section.

\section{Statistical analysis}

All data are presented as the mean \pm SEM. The statistical significance of the difference between the mean values for the different genotypes was examined using Student's $t$-test with a paired two-tailed distribution. The data were considered significant when $P<0.05$ (*) $^{*}$ or $0.01(* *)$.

\section{Acknowledgments}

We thank Li Yu, Quan Chen, Qingyuan Sun, Mofang Liu, Feng Liu, Wanzhu Jin and Zhiping Xie for their critical reading of the manuscript. We are grateful to Masaaki Komatsu for providing $\operatorname{Atg} 7^{\text {Flox/Flox }}$ mice, Jun Xia for providing GOPC-GFP plasmids. This work was supported by the National Basic Research Program of China (2011CB944303), a Knowledge Innovation Program (KSCX2-YW-N-071) and the One Hundred Talents Program of the Chinese Academy of Sciences.

\section{References}

1 Jin M, Fujiwara E, Kakiuchi Y, et al. Most fertilizing mouse spermatozoa begin their acrosome reaction before contact with the zona pellucida during in vitro fertilization. Proc Natl Acad Sci USA 2011; 108:4892-4896.

2 Berruti G, Paiardi C. Acrosome biogenesis: revisiting old questions to yield new insights. Spermatogenesis 2011; 1:9598.

3 Kang-Decker N, Mantchev GT, Juneja SC, McNiven MA, van Deursen JM. Lack of acrosome formation in Hrb-deficient mice. Science 2001; 294:1531-1533.

4 Hartree EF. The acrosome-lysosome relationship. J Reprod Fertil 1975; 44:125-126.

5 Mizushima N, Levine B. Autophagy in mammalian development and differentiation. Nat Cell Biol 2010; 12:823-830.

6 Mizushima N, Komatsu M. Autophagy: renovation of cells and tissues. Cell 2011; 147:728-741.

7 Yang Z, Klionsky DJ. An overview of the molecular mechanism of autophagy. Curr Top Microbiol Immunol 2009; 335:132.

8 Xie Z, Klionsky DJ. Autophagosome formation: core machinery and adaptations. Nat Cell Biol 2007; 9:1102-1109.

9 Komatsu M, Waguri S, Ueno T, et al. Impairment of starvation-induced and constitutive autophagy in Atg7-deficient mice. J Cell Biol 2005; 169:425-434.

10 Lomeli H, Ramos-Mejia V, Gertsenstein M, Lobe CG, Nagy A. Targeted insertion of Cre recombinase into the TNAP gene: excision in primordial germ cells. Genesis 2000; 26:116-117.

11 Xiao N, Kam C, Shen C, et al. PICK1 deficiency causes male infertility in mice by disrupting acrosome formation. $J$ Clin Invest 2009; 119:802-812.

12 Dam AH, Feenstra I, Westphal JR, Ramos L, van Golde RJ, Kremer JA. Globozoospermia revisited. Hum Reprod Update 2007; 13:63-75.

13 Zoppino FC, Halon ND, Bustos MA, Pavarotti MA, Mayorga LS. Recording and sorting live human sperm undergoing acrosome reaction. Fertil Steril 2012; 97:1309-1315. 
14 Li YC, Hu XQ, Zhang KY, et al. Afaf, a novel vesicle membrane protein, is related to acrosome formation in murine testis. FEBS Lett 2006; 580:4266-4273.

15 Mihaylova MM, Shaw RJ. The AMPK signalling pathway coordinates cell growth, autophagy and metabolism. Nat Cell Biol 2011; 13:1016-1023.

16 Zheng H, Stratton CJ, Morozumi K, Jin J, Yanagimachi R, Yan W. Lack of Spem 1 causes aberrant cytoplasm removal, sperm deformation, and male infertility. Proc Natl Acad Sci USA 2007; 104:6852-6857.

17 Hara T, Nakamura K, Matsui M, et al. Suppression of basal autophagy in neural cells causes neurodegenerative disease in mice. Nature 2006; 441:885-889.

18 Komatsu M, Waguri S, Chiba T, et al. Loss of autophagy in the central nervous system causes neurodegeneration in mice. Nature 2006; 441:880-884.

19 Yao R, Ito C, Natsume Y, et al. Lack of acrosome formation in mice lacking a Golgi protein, GOPC. Proc Natl Acad Sci USA 2002; 99:11211-11216.

20 Yue Z, Horton A, Bravin M, DeJager PL, Selimi F, Heintz $\mathrm{N}$. A novel protein complex linking the delta 2 glutamate receptor and autophagy: implications for neurodegeneration in lurcher mice. Neuron 2002; 35:921-933.

21 Kim KS, Cha MC, Gerton GL. Mouse sperm protein sp56 is a component of the acrosomal matrix. Biol Reprod 2001; 64:3643.

22 Moreno RD, Alvarado CP. The mammalian acrosome as a secretory lysosome: new and old evidence. Mol Reprod Dev 2006; 73:1430-1434.

23 Li S, Qiao Y, Di Q, et al. Interaction of SH3P13 and DYDC1 protein: a germ cell component that regulates acrosome biogenesis during spermiogenesis. Eur J Cell Biol 2009; 88:509520 .

24 Zhu GD, Salazar G, Zlatic SA, et al. SPE-39 family proteins interact with the HOPS complex and function in lysosomal delivery. Mol Biol Cell 2009; 20:1223-1240.

25 Berruti G, Martegani E. The deubiquitinating enzyme mUBPy interacts with the sperm-specific molecular chaperone MSJ-1: the relation with the proteasome, acrosome, and centrosome in mouse male germ cells. Biol Reprod 2005; 72:14-21.

26 Gnesutta N, Ceriani M, Innocenti M, et al. Cloning and characterization of mouse UBPy, a deubiquitinating enzyme that interacts with the ras guanine nucleotide exchange factor CDC25(Mm)/Ras-GRF1. J Biol Chem 2001; 276:39448-39454.

27 Paiardi C, Pasini ME, Gioria M, Berruti G. Failure of acrosome formation and globozoospermia in the wobbler mouse, a Vps54 spontaneous recessive mutant. Spermatogenesis 2011; 1:52-62.

28 Schmitt-John T, Drepper C, Mussmann A, et al. Mutation of Vps54 causes motor neuron disease and defective spermiogenesis in the wobbler mouse. Nat Genet 2005; 37:12131215.

29 Saftig P, Klumperman J. Lysosome biogenesis and lysosomal membrane proteins: trafficking meets function. Nat Rev Mol Cell Biol 2009; 10:623-635.

$30 \mathrm{Xu}$ X, Toselli PA, Russell LD, Seldin DC. Globozoospermia in mice lacking the casein kinase II alpha' catalytic subunit. Nat Genet 1999; 23:118-121.

31 Yildiz Y, Matern H, Thompson B, et al. Mutation of beta-glu- cosidase 2 causes glycolipid storage disease and impaired male fertility. J Clin Invest 2006; 116:2985-2994.

32 Lin YN, Roy A, Yan W, Burns KH, Matzuk MM. Loss of zona pellucida binding proteins in the acrosomal matrix disrupts acrosome biogenesis and sperm morphogenesis. Mol Cell Biol 2007; 27:6794-6805.

33 Audouard C, Christians E. Hsp90beta1 knockout targeted to male germline: a mouse model for globozoospermia. Fertil Steril 2011; 95:1475-1477.

34 Fujihara Y, Satouh Y, Inoue N, Isotani A, Ikawa M, Okabe M. SPACA1-deficient male mice are infertile with abnormally shaped sperm heads reminiscent of globozoospermia. Development 2012; 139:3583-3589.

35 Pierre V, Martinez G, Coutton C, et al. Absence of Dpy1912, a new inner nuclear membrane protein, causes globozoospermia in mice by preventing the anchoring of the acrosome to the nucleus. Development 2012; 139:2955-2965.

36 Young AR, Chan EY, Hu XW, et al. Starvation and ULK1-dependent cycling of mammalian Atg9 between the TGN and endosomes. J Cell Sci 2006; 119:3888-3900.

37 Deretic V, Jiang S, Dupont N. Autophagy intersections with conventional and unconventional secretion in tissue development, remodeling and inflammation. Trends Cell Biol 2012; 22:397-406.

38 van der Vaart A, Griffith J, Reggiori F. Exit from the Golgi is required for the expansion of the autophagosomal phagophore in yeast Saccharomyces cerevisiae. Mol Biol Cell 2010; 21:2270-2284

39 Guo Y, Chang C, Huang R, Liu B, Bao L, Liu W. AP1 is essential for generation of autophagosomes from the trans-Golgi network. J Cell Sci 2012; 125:1706-1715.

40 Cadwell K, Liu JY, Brown SL, et al. A key role for autophagy and the autophagy gene Atg16l1 in mouse and human intestinal Paneth cells. Nature 2008; 456:259-263.

41 DeSelm CJ, Miller BC, Zou W, et al. Autophagy proteins regulate the secretory component of osteoclastic bone resorption. Dev Cell 2011; 21:966-974.

42 Marino G, Fernandez AF, Cabrera S, et al. Autophagy is essential for mouse sense of balance. J Clin Invest 2010; 120:2331-2344.

43 Ganesan AK, Ho H, Bodemann B, et al. Genome-wide siRNA-based functional genomics of pigmentation identifies novel genes and pathways that impact melanogenesis in human cells. PLoS Genet 2008; 4:e1000298.

44 Okabe M. The cell biology of mammalian fertilization. Development 2013; 140:4471-4479.

45 Hayashi S, McMahon AP. Efficient recombination in diverse tissues by a tamoxifen-inducible form of Cre: a tool for temporally regulated gene activation/inactivation in the mouse. Dev Biol 2002; 244:305-318.

$46 \mathrm{Hu} \mathrm{XQ}$, Ji SY, Li YC, et al. Acrosome formation-associated factor is involved in fertilization. Fertil Steril 2010; 93:14821492.

47 Conner DA. Mouse embryo fibroblast (MEF) feeder cell preparation. Curr Protoc Mol Biol 2001; Chapter 23:Unit 23.2.

48 Meng J, Holdcraft RW, Shima JE, Griswold MD, Braun RE. Androgens regulate the permeability of the blood-testis barrier. Proc Natl Acad Sci USA 2005; 102:16696-16700. 
49 Sato M, Ishikawa A, Kimura M. Direct injection of foreign DNA into mouse testis as a possible in vivo gene transfer system via epididymal spermatozoa. Mol Reprod Dev 2002; 61:49-56.

50 Kishigami S, Wakayama S, Nguyen VT, Wakayama T. Similar time restriction for intracytoplasmic sperm injection and round spermatid injection into activated oocytes for efficient offspring production. Biol Reprod 2004; 70:1863-1869.

51 Kimura Y, Yanagimachi R. Mouse oocytes injected with testicular spermatozoa or round spermatids can develop into normal offspring. Development 1995; 121:2397-2405.

52 Li W, Shuai L, Wan H, et al. Androgenetic haploid embryonic stem cells produce live transgenic mice. Nature 2012; 490:407-411.

53 Wan H, He Z, Dong M, et al. Parthenogenetic haploid embryonic stem cells produce fertile mice. Cell Res 2013; 23:13301333.

(Supplementary information is linked to the online version of the paper on the Cell Research website.) 